\title{
Primary Mental Healthcare and Integrated Services
}

\author{
Marie-Josée Fleury and Guy Grenier \\ McGill University, Douglas Hospital Research Centre, Quebec, \\ Canada
}

\section{Introduction}

Mental disorder, which ranges in prevalence from 4.3 to $26.4 \%$ a year worldwide, is a critical healthcare issue (Demyttenaere et al., 2004). It is a leading cause of morbidity. Its cost and impact on productivity and on individual and family quality of life are substantial. It is associated with greater stigmatization of individuals, family burden, and a range of risk factors (for example, poverty, social isolation, criminal behavior, tobacco use, suicide attempts). Along with addiction, it is a major cause of work absenteeism and accounts for more lost work days in Canada than physical ailments (Kirby, 2006). Given the longstanding impact of mental disorder, the World Health Organization (WHO, 1978; 2001; 2008), emulated by countries such as Australia, New Zealand, the United Kingdom, and Canada (Smith, 2009), has advocated primary care reinforcement as a leading priority in mental healthcare. Primary care is defined as "the provision of first contact, person-focused, ongoing care over time that meets the health-related needs of individuals, referring only those too uncommon to maintain competence, and coordinated care when individuals receive services at other levels of care" (Starfield, 2008, p. 5). Usually, mental disorders that are considered to be managed in primary care are well-defined disorders, for which there are effective pharmacological and psychological treatments (Bower, 2002).

Robust primary care systems are deemed to achieve better organizational and patient outcomes (Starfield et al., 2005). Compared to specialized care, they are considered to be more accessible, less stigmatizing, and more comprehensive since they manage physical problems along with mental disorder (Rothman \& Wagner, 2003). Studies report that most patients with chronic conditions prefer receiving services in primary care if the quality of services is perceived as good (Upshur \& Weinreb, 2008). According to Heymans (2005), primary healthcare should handle $90 \%$ of health problems. As the main entry and service point for primary healthcare (Bambling et al., 2007), general practitioners constitute the cornerstone of the system. Every year, an estimated 75 to $80 \%$ of the general population consult a general practitioner (Nabalamba \& Millar, 2007), with up to a third of these visits for a mental disorder (Rockman et al., 2004). General practitioners see more patients with mental disorders than psychiatrists do. In Canada, about $10 \%$ of the population seek mental healthcare yearly: $45 \%$ of these patients consult a general practitioners; and $25 \%$, other healthcare practitioners (Lesage et al., 2006).

General practitioners' ability to detect, diagnose, and treat patients with mental disorder adequately, however, is often considered unsatisfactory (Walters et al., 2008; Upshur and 
Weinreb, 2008). A comparison of research interview results reveals that 30 to $70 \%$ of mental disorders in general practitioners' patients go undetected (Walters et al., 2008). However, according to longitudinal studies, after three years, only $14 \%$ of patients with depression or anxiety remained unrecognized. The literature underscores the importance of early intervention in the onset of mental disorder for better prognosis (Reavley \& Jorm, 2010). Unfortunately, the time to initial treatment contact following the onset of symptoms is generally quite long. It is estimated to range from 6 to 8 years for mood disorders and from 9 to 23 years for anxiety disorders (Wang et al., 2005a). However, compared to specialized care, it is pointed out that detection and diagnosis in primary care are more complex, concurrent disorders of physical and substance abuse being highly associated with mental disorder, and patients present with discrete illnesses and early symptoms that they themselves do not necessarily recognize (Walters et al., 2008). In addition, as general practitioner consultations last in general only few minutes, detection and diagnosis are more difficult to perform, compared to specialized care (Tyrer, 2009).

As regards treatment when mental disorder is diagnosed, Wang and colleagues (2007), comparing 10 high-income countries involved in the WHO Mental Health Survey Initiative, have provided estimates of minimum adequacy standards ranging from 18 to $42 \%$ among patients receiving treatment for anxiety, mood, and substance disorders. For depression, Mykletun and colleagues (2010) evaluated that less than $30 \%$ of patients receive proper treatment. In the province of Quebec in Canada, a recent study estimated that $54 \%$ of patients diagnosed with major depression and covered by the public drug insurance plan stop taking their medication before six months, in spite of best-treatment guidelines (Conseil $d u$ médicament, 2011) that recommend taking them at least for eight months. Moreover, only $31 \%$ of these patients consult their general practitioners at least eight times, wherever guidelines prescribed a minimum of ten visits (Conseil du médicament, 2011). In a similar study in the Netherlands (Seekles et al., 2009), about 30\% of patients stopped using antidepressant medication within the first month of treatment, while $40 \%$ reached the recommended therapeutic dosage of the antidepressant drug.

In addition, a number of studies have revealed instances of fragmentation and duplication of services or major gaps in the range of mental healthcare systems, resulting in inefficient provision of care, and in preventable emergency-room visits or hospitalizations (Bachrach, 1996; Provan \& Milward, 1995). The lack of integration between primary and specialized care, and of interdisciplinary collaboration has also received repeated mention in the literature (Fleury, 2006). Globally, the primary healthcare system has "often been viewed as poor care for poor people" (Desjardins, 2011, p. 10). Therefore, to help general practitioners manage patients with mental disorders more effectively, great efforts have been made, particularly in the past decade, to develop models of integrated care and best practices in the field of primary mental healthcare services.

On the basis of an international literature review of primary mental healthcare and two research projects focusing on general practitioner management of patients with mental disorder in Quebec, this chapter examines patient profiles in primary mental healthcare, determinants of service utilization of these patients, and primary mental healthcare reforms with a spotlight on best practices. The research projects are designed to describe the clinical and collaborative role of general practitioners in mental healthcare, uncover enabling and hindering factors associated with the management of patients with mental disorder, and cast light on general practitioners' strategies and recommendations to improve patient management. The Quebec/Canada public mental healthcare system offers an interesting 
setting for exploration of these topics. It has undergone significant transformation over the years in efforts to reinforce primary mental healthcare and integrated care; however, the quality of Canada's primary healthcare system and ease of accessibility rank poorly compared to international best practices (Katz et al., 2009). As a result, improvement is needed. As increasing attention worldwide is devoted to the development of optimal integrated models of primary care, this chapter makes a contribution to the discussion surrounding service planning in the field of mental healthcare. It also considers the most effective components and strategies for enhancing care collaboration and integration. While it focuses on research in a specific context (Quebec/Canada), this chapter is of wide-ranging interest and relevance since primary mental healthcare in most industrialized countries (including the United Kingdom, Australia, Ireland, and the United States) share similar reform objectives and organizational and practice features (Gask et al., 2008).

\section{Methods}

\subsection{Study population and data collection}

This chapter is based on a major literature review on primary mental healthcare, including both epidemiological and organizational research initiatives. General practitioner data from Quebec presented in this chapter were sourced from two studies. The first study (conducted using a cross-sectional design) targeted all general practitioners from nine Quebec local healthcare networks in five administrative healthcare regions (Quebec features 18 regions and 95 local networks), corresponding to $20 \%$ of the general practitioner population in the province. Quebec is the second most populated province in Canada, with about 7.9 million inhabitants (23\% of the Canadian population). The province is home to 7,199 equivalent fulltime general practitioners (1 GP per 1,041 inhabitants) (Savard \& Rodrigue, 2007). In Quebec, local healthcare networks constitute the core of the healthcare system, where providers combine primary and specialized care services to ensure a comprehensive care spectrum (Fleury, 2006). The local healthcare networks selected for this study represent urban, semi-urban, and rural areas; some of these networks include university-affiliated psychiatric facilities. They encompass diversified work settings for general practitioners: solo private clinics; group private clinics; walk-in clinics; community care centers; family medicine groups; network clinics; and hospital centers (acute, psychiatric, or long-term). Family medicine groups correspond to a primary care setting where patients are registered with general practitioners ( $n=8$ to 10 equivalent full time), and where nurses work closely with general practitioners; nurses are responsible for patient screening, follow-up, and referral. Network clinics ( $n=10$ or more general practitioners equivalent full time) are similar, but patients are not registered with general practitioners and nurses act mainly as liaison agents, coordinating services between organizations. In community care centers, interdisciplinary teams are onsite.

To select the study sample, a list of all general practitioners in the nine local healthcare networks was provided by the Quebec Federation of General Practitioners (FMOQ), which represents all Quebec general practitioners. Every general practitioner in these local healthcare networks $(n=1,415)$ was asked to participate in the study. The survey was mailed from September 2005 to February 2007. The Quebec public register for all general practitioner medical acts (Régie de l'assurance maladie du Québec (RAMQ) database, 2006) was also analyzed to compare the study's sample with the general practitioner population of Quebec as a whole wherever possible for the purpose of data validation (for example, gender, age, types of 
territories, diagnoses). More information on the instruments and study methods employed are provided in other publications (Fleury et al., 2008; 2009; Ouadahi et al., 2009).

The second study arose from the first. Out of the general practitioners who participated in the initial research initiative, 60 physicians (12 per region) where selected for qualitative investigation in efforts to enhance understanding of mental disorder management. Recruitment took place from April 2009 to March 2010. A 27-item questionnaire and interview guide were used. Both instruments were tested on three general practitioners not included in the final sample. The questionnaire, a shorter version of the survey used in the previous research project, covered four dimensions: (1) general practitioners' sociodemographic profile and practice location; (2) continuing medical education; (3) clinical practice features and profile of patients with mental disorder; and (4) comfort level in managing patients with mental disorder. It included categorical or continuous items, with some 5 or 10-point Likert Scale questions. It was self-administered and required 10 minutes to complete. Development of the interview guide was based on a literature review of primary care and the previous research project. The guide included three sections, relating to general practitioners': (1) clinical practice; (2) relationships with mental healthcare networks, evaluation of availability of mental healthcare resources in their territory, and views on healthcare reform; and (3) needs for support and collaboration and ideal practice models for treating mental disorder. Seventy-minute interviews were conducted $(25 \%$ faceto-face and $75 \%$ by phone), recorded, and transcribed (with respondents' anonymity respected throughout). All participants from both studies signed a consent form approved by the research ethics board at the Douglas University Institute of Mental Health.

\subsection{Data analysis}

Quantitative and qualitative analyses were carried out. Quantitative investigation involved descriptive and inferential statistics, computed with SPSS Statistics 17.0. Analyses are well described in other publications (Fleury et al., 2008; 2009; 2010a). As for qualitative data (the second study), transcripts were read by the research team and subsequently coded using NVivo 8. The codes were derived from the primary-care literature on themes in the interview guide. Transcript analysis generated new codes. The researchers ensured coding accuracy and refined the interpretation of results. Data analysis also involved the reduction and synthesis of information. Reports integrating quantitative and qualitative data were produced to summarize pertinent results, which were read and discussed by all researchers. In addition, a second-step analysis was performed using data associated with general practitioners' main practice settings (where general practitioners spent most of their work hours), for example, solo private clinics, community care centers, and so on. Data-grouping permitted comparison of general practitioner collaborative practices with respect to their main settings. Wherever pertinent, data analysis also compared general practitioners' collaboration strategy for patients diagnosed with common mental disorder (for example, anxiety, depression) and patients with serious disorders (schizophrenia, bipolar disorder) with or without concomitant disorders (for example, physical problems, substance abuse).

\section{Contextual background}

\subsection{Profiles of patients with mental disorders}

The concept of mental health is usually considered in terms of an ecological model that includes, beyond the illness, individuals' adjustment within their communities, the state of 
their well-being, and their self-fulfillment (empowerment). This conception leads to interventions that are not only medical but also psycho-social (for example, psychotherapy, psycho-education and rehabilitation). Mental disorder, for its part, is defined as "clinically significant conditions characterized by alterations in thinking, mood (emotions) or behavior associated with personal distress and/or impaired functioning" (WHO, 2001, p. 21). Mental disorder is generally classified as "common or moderate" or "severe." Generally, common mental disorders are viewed as the main focus of primary mental healthcare (Bower \& Gilbody, 2005).

The major common mental disorders are mood disorders and anxiety disorders. One of the most widespread mood disorders is major depression. Alcohol use is also quite common. According to the Canadian Community Health Survey (CCHS), the incidence of major depression for a given year is $4.5 \%$, and for mood disorders as a whole $4.9 \%$ (Statistics Canada, 2002). International surveys suggest, however, that the incidence of mood disorders, for a given year, is estimated at $9.5 \%$ in the United States (Kessler et al., 2005), 8.5\% in France, $6.9 \%$ in Netherlands, and only 3.6\% in Germany, for instance (Demyttenaere et al., 2004). According to the CCHS, the incidence of anxiety disorders in a given year was $1.6 \%$ for panic disorders, $0.7 \%$ for agoraphobia, and 3.0\% for social anxiety disorders, and $4.7 \%$ as a whole (Statistics Canada, 2002). International surveys suggest that the overall incidence of anxiety disorders is $18.1 \%$ yearly in the United States (Kessler et al., 2005), $12 \%$ in France, $8.8 \%$ in Netherlands, and $6.2 \%$ in Germany (Demyttenaere et al, 2004). In the Epidemiological Catchment Area Study (Regier et al., 1990), the lifetime incidence for alcohol and drug abuse in the population was evaluated at $17 \%$. The CCHS reported that an estimated 4.6 to $1.9 \%$ of the Quebec population experience mild to serious alcohol consumption problems yearly (Statistics Canada, 2002).

The most prevalent serious mental disorders are schizophrenia, bipolar disorder, and delirious disorder. Patients with serious mental disorder usually differ substantially from patients with common mental disorder. Serious mental disorder patients (2 to $3 \%$ of the population) are generally unemployed and need considerable help in many biopsychosocial domains on a long-term basis (Nelson, 2006). Patients with common mental disorders are generally employed (or on sick leave when ill); their problems are often less disabling though they may be recurrent, relapse or become chronic. In a systematic needs-assessment literature review (Joska \& Flisher, 2005), patients with mental disorder are reported to experience between 3.3 and 8.6 needs, depending on their mental disorder profile; patients with less severe diagnostics usually have fewer needs than patients with mild or moderate mental disorder. Psychotic symptoms, company, daytime activities and psychological distress are usually the domains with the highest incidence of needs (Hansson et al., 2001). Unmet needs are more predominant in needs domains related to interpersonal relations like company, intimate relationships, and sexual expression (Middelboe et al., 2001).

The incidence of mental disorder is higher among adults (aged 18 to 64). However, the first manifestations of mental disorder often occur in adolescence and early adulthood. According to the Canadian Community Health Survey (CCHS), $47.9 \%$ of adults from 45 to 64 years, and $34.1 \%$ of seniors have indicated that their mental disorder appeared before the age of 25 (Government of Canada, 2006). On average, common mental disorder is more widespread among women than men. Depression and anxiety in particular are more prevalent among women. However, addictions and antisocial personality disorders are more common among men. Serious mental disorders, like schizophrenia, are as frequent in men as in women, but men usually develop this mental disorder earlier than women 
(Mueser \& McGurk, 2004). Moreover, a significant proportion of the population is affected by more than one mental disorder (particularly concurrent anxiety and depressive disorders). In a study by Kessler and colleagues (2005), out of an overall incidence of $26.2 \%$ for mental disorder in a given year, $14.4 \%$ of the sample had a single mental disorder, $5.8 \%$ had two types of mental disorder, and $6.0 \%$ had at least three types of mental disorder. The recurring nature of mental disorder makes managing these problems more complex. Lloyd and colleagues (1996) followed a cohort of patients with mental disorder treated in general practice: they noted that after 11 years $54 \%$ still had specific problems and $37 \%$ had had other episodes of illnesses likely associated with chronic mental disorder. It has also been reported that more than $75 \%$ of patients with depression relapse or experience recurrence (Howell et al. 2008); this finding substantiates the relevance of close monitoring and longterm approaches to care.

The magnitude of co-morbid conditions associated with mental disorders (more frequent with increasing age) is very high. The combination of concurrent problems can result in a more negative prognosis and make it less likely that a person will stick to a particular medical regimen. For example, according to the Canadian Community Health Survey (CCHS), 66\% of Canadians suffering from depression in the past 12 months also present at least one chronic condition (Schmitz et al., 2007). The most common physical concurrent problems related with mental disorder are cardiovascular, gastrointestinal, and lung diseases, diabetes, and neurological disorders (for example, Parkinson's disease or epilepsy) (Jones et al., 2004). Concurrent substance abuse problems were also found in about 15 to $50 \%$ of individuals with serious mental disorder, especially bipolar disorder (Skinner et al., 2004). Nearly $60 \%$ of homeless individuals (Weinreb et al., 2005) and from 15 to $35 \%$ of individuals with intellectual disabilities may also suffer from mental disorder (Ministère de la Santé et des Services sociaux du Québec, 2006). In addition, suicide is from 10 to $20 \%$ more prevalent in individuals who have schizophrenia or who have had depression or an anxiety disorder (Statistics Canada, 2002).

It is worth noting that the incidence of mental disorder may vary significantly from one study to another, depending on the country where the survey was conducted, types of mental disorder included in the survey (for instance, most serious disorders and personality disorders are not included), measurement instruments employed (survey, database or administrative records), and types of population studied (general population or clinical sample). DSM-IV and ICD-10 are the most widely used diagnostic systems. As regards anxiety disorders, Kessler and colleagues (2010, p. 31) have suggested that "the current DSM and ICD definitions might substantially under-estimate the proportion of the population with a clinically-significant anxiety condition." Finally, although diagnosis is an important factor for service planning, a more comprehensive view of individuals is necessary to establish appropriate service offerings (for example, social support, socioeconomic profile, and history of illness).

\subsection{Determinants of service utilization of patient with mental disorders}

In general, mental health service utilization is most closely associated with needs-related factors, such as having the following diagnoses: schizophrenia (Leaf et al., 1985); major depression (Leaf et al., 1985); anxiety disorders (Leaf et al., 1985); antisocial behavior (Leaf et al., 1985); and maternal history of mental disorder (Mojtabai et al., 2002). Previous studies have reported that severe mental disorder cases were associated with more intensive service utilization than mildly severe or moderate cases (Tempier et al., 2009; Wang et al., 2007). 
Number of diagnoses or needs and concurrent disorders are positively associated with higher service utilization. Individuals with concurrent mental disorder and substance abuse usually reported the highest utilization rates, and the least favorable selfperception/assessment of good health (Rush et al., 20010). Substance abuse alone is related to very low service utilization (Tempier et al., 2009). Attitudes and beliefs regarding mental disorder and treatment also play a role in service utilization. High rates of health service use have been found among individuals who consider their mental health to be poor (Leaf et al., 1985). Generally, the more serious the mental disorder diagnosis and its symptoms are and the greater the number of serious needs and co-morbid health conditions, the greater is the use of services and the poorer the prognosis.

Socio-demographic factors are also closely related to service utilization. Age, gender, marital status, education, country of birth, and race/ethnicity are important determinants of service utilization among individuals with mental disorder. Several studies have found that younger (18 to 24$)$ and older (65 and up) individuals are less likely to use services than participants aged 25 to 64 (Wang et al., 2005a; Kessler et al., 2001). Females are the most frequent users of health services, principally of general practitioners; men are more likely to seek specialized services (Vasiliadis et al., 2007; Carr et al., 2003; Narrow et al., 2000). Generally, studies have found that persons who were previously or currently married used services more often than bachelors (Vasiliadis et al., 2007; Wang et al., 2005b; Bebbington et al., 2000; Parslow \& Jorm, 2000). Individuals with more education (Vasiliadis et al., 2007; Leaf et al., 1985) also use health services significantly more often than less well-educated persons, despite the higher incidence of mental disorder among the latter (Olfson et al., 2002). Individuals with more elevated socio-economic status tend to use specialized services more assiduously, particularly psychiatric and psychological care, even among individuals with comparable insurance coverage (Wang et al., 2000; Hendryx \& Ahern, 2001; Alegria et al., 2000). With regard to country of birth, race, and ethnicity, studies found that Caucasians are more likely to use health services than Blacks or immigrants (Vasiliadis et al., 2007; Hatzenbuehler et al., 2008; Keyes et al., 2008).

Professional and social support (including family and friends) also plays a role (Lemming \& Calsyn, 2004; Bonin et al., 2007). Social support can be positively or negatively associated with service utilization for mental healthcare reasons (Carr et al., 2003; Pescosolido et al., 1998; Albert et al., 1998). Some social networks help individuals to recognize their problems and seek aid from health providers; other networks tend not to encourage members to seek help, thereby constituting a barrier to accessibility (Howard et al., 1996). Perceived barriers to accessibility to care are negatively associated with service utilization (Leaf et al., 1985). Access to a regular source of medical care (or continuity of care) is positively associated with service utilization (Leaf et al., 1985). Compared to users of primary care only, individuals who sought both primary and specialized care for a mental disorder presented more mental disorders and lower quality of life. Individuals using only specialized healthcare received significantly less social support than persons using primary care exclusively and lived in neighborhoods with a high proportion of rental housing (Fleury et al., 2011). Generally, a positive response to pharmacotherapy, compliance with drug treatment, low number of acute-care hospitalizations, and satisfactory outpatient services play a central role in the patient recovery process (Casper \& Donaldson, 1990; Breier et al., 1991; Korkeila et al., 1998). Lastly, failure to seek treatment or abandoning treatment is often explained by the belief that a mental health disorder will resolve on its own and by the fear of being stigmatized (Fournier et al., 2007). Denial of illness is also very frequent among heavy users of 
mental healthcare services, which impedes their recovery (Kent et al., 1995; Kent \& Yellowlees, 1995).

\subsection{Mental health primary care reforms and best practices}

In Canada (including Quebec), as in other industrialized countries, major reforms are underway to reinforce primary care and collaboration among providers. Led by the Government of Canada with the Health Transition Funds, major grants were distributed between 2000 and 2006 to support primary healthcare transformation at the provincial level (Bergman, 2007) as health and social services are a provincial jurisdiction in Canada. In 1997, the College of Family Physicians of Canada and the Canadian Psychiatric Association produced a joint position paper on shared mental healthcare in Canada (Kates et al., 1997). These initiatives encouraged reform within the primary mental healthcare system. In Canada, as in other countries such as the United Kingdom and Australia, strengthening primary mental healthcare and integration between providers are key issues (Bosco, 2005).

Mental primary healthcare reforms are designed to improve access, continuity and quality of care, and the management of mental disorder. Reforms target general practitioners' modes of practice and payment. General practitioners are increasingly encouraged to work in group practice and multidisciplinary settings. In Canada, $60 \%$ of general practitioners work in private physician-run clinics, and a minority $(8.3 \%)$ in public governance models such as community care centers (College of Family Physicians of Canada, 2004); 23\% work in solo practice, $51 \%$ in group practices, and $24 \%$ in multidisciplinary team practices (College of Family Physicians of Canada, 2008). In 2007, about 39\% of Canadians 18 and over said they had access to an interdisciplinary team of primary care providers (Khan et al., 2008). A large number of general practitioners in Canada and the U.S. are deserting primary care; in addition, recruitment in family medicine school is more difficult than in other countries. About $40 \%$ of general practitioners work partly in hospitals, and the same proportion in walk-in clinics (College of Family Physicians of Canada, 2004). In Quebec, this situation has produced a considerable impact. Close to $25 \%$ of the population in the province lack a family physician; accordingly, patient volume at walk-in clinics is high. One study (Haggerty et al., 2004) estimated that walk-in clinics were a regular source of care for $60 \%$ of patients in some regions of Quebec. However, there is worldwide upswing in the number of general practitioners working in group and multidisciplinary settings or public governance models (McAvoy \& Coster, 2005; Bourgueil et al., 2007).

In current primary care reforms, patient rostering is also promoted. Financial incentives are geared toward patient rostering, but also toward targeted disease detection rates and patient outcomes (as in the United Kingdom) or the management of patient with complex or severe illnesses who are rostered (as in Quebec and Ontario). In opposition to fees for services, other payment structures such as salary, hourly fees or mixed compensation modes are also actively encouraged, especially for the management of complex or chronic care patients (the United Kingdom, Spain, and Italy have developed these models). In Canada (similarly to the United States, France and Germany), general practitioners are paid mainly through fees for services (about $73 \%$ ), but also partly through salary in community care centers or an hourly fee in hospitals. Over the years, in Canada the number of general practitioners working outside fees for services has increased; this also seems to be a trend at the international level (Simonet, 2009).

Well-designed reform of primary mental healthcare embraces the full continuum of care, focusing on comprehensive patient needs and better integration between providers. Access 
to increasingly systematic and proactive psychosocial follow-up services, psychotherapy (especially cognitive behavioral therapy), and patient self-management are central developments within current reforms. Incentives promoting implementation of best practices and innovations are also in place. Specifically, in order to help general practitioners manage patients with mental disorder more effectively, efforts are being made to develop approaches, instruments or guidelines, and collaborative care models with demonstrated efficacy. Models of optimally effective mental healthcare encompass a broad range of management and clinical tools, including: stepped care, shared care, case management, patient self-management, psychometric diagnostic tools for increasing screening, clinical protocols or evidence-based treatment guidelines, continuous education, and computerized management systems (Craven \& Bland, 2006). They are part of coherent integrated organizational models such as the chronic care model, integrated service networks or patient-centered medical home approaches. These care models acknowledge the considerable interdependence among providers. Optimally effective integrated care models are also supported by major government mental healthcare policy initiatives (Smith, 2009).

Overall, compared with services as usual, coherent and integrated care models encompassing multimodal strategies have demonstrated better clinical outcomes, more efficient use of resources, and enhanced patient experience of seeking and receiving care, especially in the case of patients with chronic or complex problems such as major depression (Kates et al., 2011; Katon et al., 2007; Williams et al., 2007; Smith 2009). The availability of evidence varies according to the models or strategies studied (for example, shared care, clinical protocols) and types of clientele (severe depression being the illness mainly studied in primary mental healthcare). Generally, the quantity and quality of evidence is limited in most models and strategies. It is unclear which patient profiles as targeted by reform would lead to the best income; therefore, more research is required (Walters et al., 2008). In addition, even if major progress has been realized in the past decade, most of the models or multimodal strategies cited above are in the early stage of implementation, as is the case in Canada and Quebec (Kates et al., 2011; Pawlenko, 2005). According to Walters and colleagues (2008), the challenge ahead is to define which component of complex multimodal interventions are important and for which patient profiles and determine how well they can be incorporated into different primary care integrated models.

Integrated care models or multimodal strategies are not incompatible with one another and can easily be combined. They illustrate approaches and strategies designed to: (1) improve general practitioners' ability to manage mental disorder, including patient self-management support; (2) reinforce support and coordination between general practitioners and specialized care professionals; (3) extend biopsychosocial services through greater collaboration with psychosocial teams and more services supplied in the community (on an outpatient basis); (4) transfer patients to specialized care during crisis periods with subsequent follow-up by a general practitioner and other psychosocial practitioners in the community as needed; or (5) organize overall care network more efficiently for improved healthcare provision, efficiency, and outcomes.

One of the best-known models, extensively studied and increasingly implemented for several illnesses (for example, hypertension, congestive heart failure, diabetes, and depression) is the chronic care model (Wagner et al., 2001). With its focus on improving general practitioners' clinical practice and team collaboration, the chronic care model also encompasses holistic care. It revolves around: (1) organization of services and delivery; (2) 
patient self-management support; (3) clinical decision support; (4) clinical information systems development; (5) use of community resources; and (6) community-inclusive healthcare organization (Bodenheimer et al., 2002). Contrary to the chronic care model, integrated service networks (also known as organized delivery systems, integrated delivery systems, and disease management) focuses on the organization of the full network of care spectrum for patients needs, including coordination of the functional or administrative, clinical and medical components of the care process (Fleury, 2006). Integrated service networks are defined as a set of autonomous organizations that distribute a continuum of coordinated services to a defined population (Shortell et al., 1994). These organizations are held financially and clinically accountable for achieving efficient results and improving the health and well-being of the population they serve. Integrated service networks are based on an acknowledgment of considerable interdependence among players and organizations, usually developed in local settings (for the purposes of feasibility). As for the patientcentered medical home approach, it is designed to provide comprehensive primary care services for patients. It was first applied to children with special healthcare needs, but has since been extended to adults as well. It focuses on the general practitioner-patient relationship (including, when appropriate, the patient's family), patient rostering, continuity, and access to care (Cruickshank, 2010). This approach emphasizes the right of patients to be managed by a general practitioner who acts as a coordinator of a multidisciplinary team of healthcare professionals (a challenge in settings where there is a shortage of general practitioners). Leading physician groups in the United States and Canada have endorsed this model as a means of improving primary healthcare (College of Family Physicians of Canada, 2009). Compared with integrated service networks (which focus on the macro level) and the chronic care model (meso level), the patient-centered medical home approach targets the micro level of care.

Stepped care implies a progression from light to intensive treatment or to low-cost community-based treatment before high-cost institutional or specialized services according to patient need profiles (Seekles et al., 2009). The selection of treatment steps depends on patient profiles (for example, the severity of patients' illness, their socio-demographic characteristics, and social support). Stepped care simplifies the patients' care pathways, promotes their active engagement toward recovery and prevention of relapse, and uses limited resources to the greatest effect for a population-wide level of care. Treatments are monitored systematically; if they do not lead to adequate results, stepping-up is recommended. Stepped care is particularly relevant for minor disorders, without adverse consequences, and when a set of treatment alternatives coexist. In such cases, it initially relies on less expensive interventions such as self-help approaches, bibliotherapy, computerized treatments, including lifestyle changes, problem-solving, psycho-education, and motivational interviewing. When combined with previous interventions, minimal telephone follow-up for assistance in attainment of or adherence to medication is usually perceived to be more effective. If needed (as ulterior steps), brief individual or group therapy may be required, usually based on cognitive behavioral therapy (Walters et al., 2008) or more extensive and specialized care. For instance, the best-practice treatment recommendation for depression in use at the National Institute for Health and Clinical Excellence (NICE, United Kingdom) includes five treatment steps (Tylee, 2006). In Step 1, patients with mild depression are fully managed by general practitioners (early detection is also greatly encouraged). In Step 5, patients with severe depression presenting risk of dangerousness or suicide are managed by a specialized psychiatric care team. 
Shared care involves coordination among general practitioners, psychiatrists, mental healthcare resources, and the voluntary sector (for example, food bank, self-support groups). In its early implementation stage, it focused primarily on general practitioners and psychiatrist collaborations. Now, it has been extended to psychosocial mental healthcare professionals (including the voluntary sector) and is referred to increasingly as "collaborative care" (Kisely \& Campbell, 2007; Kates et al., 2011). Several taxonomies of shared-care models coexist. The most commonly cited are the shifted outpatient, community consultation-liaison, and attachment models (Craven \& Bland, 2006). The shifted outpatient scheme, which has been broadly implemented, involves general practitioners remaining in their practices and referring patients to psychiatric teams in outpatient clinics. The two other models have been less extensively deployed. In community consultation-liaison, psychiatric consultations are provided to general practitioners to help them manage difficult patients or advise them on best practices. The attachment scheme is built on the previous model and involves part-time psychiatrists and psychosocial mental health professionals assigned to general practitioners' clinics. In Bower and Gilbody (2005), another interesting model of "quality improvement in primary care mental health" is presented with two components related to shared care: consultation-liaison and collaborative care. The former includes strategies designed to improve general practitioners' training in mental healthcare and referral to specialized care when needed (minority of cases); here, training is provided by mental healthcare specialists. The latter is built on the previous component and features the addition of case managers who liaise with general practitioners and mental healthcare specialists. Overall, the different models of shared care developed to date vary with regard to the intensity of assistance provided to general practitioners by psychiatrists and other psychosocial mental healthcare professionals. Best models depend on the context (for example, practice settings, network organization of care) and patient profiles. Shared-care component models can include the following: (1) informal care support for general practitioners by psychiatrists; (2) "specialized mental health general practitioners" - i.e., general practitioners are both trained in physical medicine and psychiatry; (3) formal and more rapid referral process and efficient telephone support from psychiatrists; and (4) onsite mental healthcare specialists into the general practitioners' surgeries, which imply general practitioners' consultations with mental healthcare specialists (psychiatrists or other psychosocial professionals such as case managers), patients' consultations with psychiatrists or both general practitioners and psychiatrists, and linking patients with case managers, including follow-up with a general practitioner (Morden et al., 2009).

As the mental healthcare literature reveals, a key feature of shared-care models is the increasingly important role played by case managers, a source of systematic and proactive psychosocial follow-up, which involves screening, patient psycho-education, subsequent treatment (including drug adherence), and patient self-management techniques. Assigning case managers to patients with mental disorder has been advocated as a means of reducing hospital admissions, promoting community-based care, and enhancing patient quality of life (Fitzpatrick et al., 2004). According to Fleury and colleagues (2010b), the presence of a case manager was the most significant variable associated with the use of primary care services by individuals with serious mental disorder (mainly schizophrenia). Case managers (offering personalized follow-up arrangements) are increasingly called on to play a major role in connecting patients with services in appropriate and cost-effective ways to fulfill patient needs at, increasingly, the offices of general practitioners. 
Another development in current mental healthcare reforms is the reinforcement of access to psychotherapy as an alternative to drug treatment or a form of complementary care designed to meet the comprehensive needs of patients. Some patients have strong resistance to psychopharmacological treatment (for example, fear for stigmatization, side effects or dependency), particularly when drugs are taken for a long period (Howell et al., 2008). The use of psychotherapy compared to medication is also found to be more effective in the long term; however, the latter results in more rapid patient recovery (Howell et al., 2008). When compared to practices in several developed countries such as Australia, the United Kingdom, the Netherlands, and other nations in Europe (Hakkaart-van Roijen et al., 2006), non-pharmacological treatment in primary care Canada for common mental disorder is more limited (Myrrh \& Payne, 2006). In 2001, approximately $80 \%$ of consultations with psychologists were within the private system, with a proportion of costs covered by private insurance or out-of pocket spending (Moulding et al., 2009). In Quebec, however, psychosocial services have been considerably reinforced in community care centers for the management of common mental disorder. The reform launched in 2005 was designed to develop a mental healthcare team of 20 full-time psychosocial professionals along with two general practitioners assigned to each team for a total population of 80,000 adult patients. Over the past decade, major initiatives have been undertaken in Australia (Outcomes in Mental Health Care Program, 2001; Better Access, 2006, as cited in Howell et al., 2008) and the United Kingdom (Improving Access for Psychological Therapies program, 2007, as cited in Clark et al., 2009) to provide people who suffer from mental disorder with more streamlined access to psychotherapy as an alternative or complement to pharmacological treatment. In the United Kingdom, close to 10,000 new therapists have been assigned to operate the mental healthcare system, under the close supervision of psychologists and psychiatrists (Mykletun et al., 2010). As part of these initiatives, improving mental healthcare training (for general practitioners and psychosocial professionals especially in the area of cognitive behavioral therapy) and collaboration between practitioners were key reform features. Recent studies show that enhanced access to psychosocial care in the treatment of mental disorder and closer cooperation among general practitioners and psychologists resulted in improved patient care, positive patient outcomes, and greater satisfaction among general practitioners, without increasing healthcare costs (Clark et al., 2009; Layard et al., 2007; Chomienne et al., 2010).

In all aforementioned models or strategies of current primary mental healthcare reform, patient self-management is a key orientation. It is a core component of the chronic-care model, the patient-centered medical home approach, stepped care, and psychosocial intervention. In the Canadian province of British Columbia, for example, 700 general practitioners were recently trained to apply this approach in their practice (Bilsker, 2010). Patient self-management includes self-help materials, bibliotherapy, and interactive web programs based on psychological treatment. It aims to provide information on diseases and treatment options, but also on practices designed to foster lifestyle changes, effective problem-solving, and improvement-oriented motivational behavior. It enhances participation in care process and patient empowerment. Increasingly, research underscores the importance of patient choice and engagement in improving treatment outcomes (Kisely \& Campbell, 2007). Patient self-management is also perceived to be cost-effective; it can be easily implemented at a population-wide level, targeting mild and early cases of mental disorder. It is proving increasingly effective; however, more research is needed. It can be promoted as a first step in the care of patients with mild mental disorder or encouraged as a treatment strategy in a comprehensive care package for more complex cases. 
At last, other strategies worth mentioning for reforming the primary mental healthcare system are evidence-based treatment guidelines or screening tools, continuous education, and computerized management systems. Since the 1990s, there has been an increase in the number of clinical guidelines. While many efforts have been made to standardize and promote best clinical practices, studies generally reveal the difficulty of implementing them in actual practice settings, the low rates of treatment adherence, and the slight (if any) improvement in patient outcomes produced by both guidelines and screening tools (Collins et al, 2006; Walters et al., 2008; Seekles et al., 2009). Inadequate implementation is partly explained by the fact that such intervention does not always closely correspond to the problems faced by general practitioners (van Rijswijk et al., 2009). Walter and colleagues (2008) have suggested reserving screening tools to high-risk groups (for example, patients with chronic physical illness, unemployed or experiencing bereavement). Since the production of guidelines has resulted in a great of duplication of efforts, a new trend has developed, namely, to adapt gold standard quality tools (such as the ones designed by the National Institute for Health and Clinical Excellence (NICE) in the United Kingdom) to the local context to organize services (Fervers et al., 2006). Research also reveals that continuous education or training does not always lead to outstanding results; in fact, training is often reported as being ineffective (Mykletun et al., 2010). In their review of training practices, Bower and Gilbody (2005, p. 841) reported the following paradox: "Training that is feasible within current educational structures (such as guidelines and short training courses) is not effective, whereas more intensive training is effective but may not be feasible." Crosstraining is an example of effective learning. It involves the presence of various professionals working in the same field (for example, mental healthcare) in a local territory. It consists as a leaning strategy which integrates a set of interrelated techniques (for example, clarification, observation, and personal rotation) patterning to a specific topic, enabling the emergence of inter-positional knowledge of partners and community of practice (Perreault et al., 2009). Overall, clinical standardized screening or guidelines and training are effective when used as part of a comprehensive care package and management program that is continually updated.

Computerized management systems, especially electronic medical records, are also central to healthcare system reform, but have been found to be effective only if they include a broad range of features and are integrated within a coherent knowledge-management structure. Features may include: access to test results; drugs registration; patient history and clinical profile; and formal referral procedure. List of patients may also be produced for more effective management (for example, by illness, prescribed medication, specific risk profiles), for preventive measure or screening, or for follow-up or subsequent treatment. Guidelines designed to foster knowledge transfer or support clinical decision-making may also be integrated (Dorr et al., 2007; Commissaire à la Santé et au Bien-être, 2010). Computerized management systems have been reported to improve access to test results, referrals, and claims processing; improve staff time-management leading to greater productivity; reduce the number of return visits to emergency rooms; decrease the incidence of misdirected referrals and, consequently, the number of follow-up visits with specialists (Fontaine et al., 2010). In comparison to countries such as the United Kingdom, New Zealand, and Australia, the implementation of such electronic systems in Canada and the United Stated has been very slow. In both countries, about $20 \%$ of physicians have reported using such electronic systems (comprising only some of the features mentioned above) (Commissaire à la Santé et au Bien-être, 2010; Fontaine et al., 2010). Few patients are also able to communicate by e-mail 
directly with their general practitioners (The Commonwealth Fund, 2008 as cited in Commissaire à la Santé et au Bien-être, 2009). There are numerous challenges associated with the deployment of electronic systems, which account for the lagging development, including (to mention only few hindering factors): their complexity combined with a quickly evolving environment in which knowledge is constantly being produced; the fact that the healthcare system is segmented; substantial funding requests and changes to practices; and the potential of disclosing personal and confidential information unwittingly. Finally, while the challenge of implementing electronic medical records is significant, all the strategies and models described above do not stand alone, they must be integrated in a coherent primary care package and organized service structure, which are undergoing sweeping changes in hopes of improving both systems and patient outcomes (Upshur \& Weinreb, 2008).

\section{Results of the two research projects on Quebec general practitioners}

\subsection{Socio-demographic profile of general practitioners participating in the two studies} Of the 1,415 targeted general practitioners, 353 were excluded since they had retired or moved to another area or could not be reached either by phone or e-mail. Subsequently, 37 questionnaires were excluded as they were not duly completed. The final sample comprised 398 subjects for a response rate of $41 \%$. The sample was compared to non-responding general practitioners for gender distribution, which yielded a non-significant result $(x 2=3.44$; $\mathrm{df}=1 ; \mathrm{P}=0.0637$ ). Comparisons were also made between the study sample and Quebec's general practitioner population as a whole, regarding gender, age, clinical practice settings, territory of practice, income level from fees for services, and volume of patients with mental disorder. No significant difference was found in any of these comparisons. When data were available, comparisons were made between the general practitioner population in Quebec and Canada. Significant differences were found between the study sample $(n=398)$ and Canadian general practitioners only regarding gender (51.3\% female in the sample vs $36.7 \%$ for Canadian general practitioners; Chi-square: 3.98; P value: 0.046) and income from fees for services (65\% vs 51\%, Chi-square: 4.02; P value: 0.045) (Pong, 2005; College of Family Physicians of Canada, 2007). In addition, the two samples, namely, 398 general practitioners in the initial study (quantitative investigation) and 60 general practitioners in the subsequent study (qualitative investigation), were compared for key parameters: age, sex, and fee-for-service income. No significant differences were found. However, the sample that included 60 general practitioners earned a great deal less income from service fees than Quebec's general practitioner population as a whole.

\subsection{General practitioner management of patients with mental disorders (clinical and collaborative practices)}

According to the Quebec public register for all general practitioner medical acts (known as the RAMQ database), $15 \%$ of the Quebec population aged over 18 consulted a general practitioner for a mental disorder. The survey of 398 general practitioners $(20 \%$ of Quebec's general practitioner population) also revealed the high incidence of mental disorder-related consultations in general practitioners' surgeries. About one quarter of all medical visits were associated with mental healthcare - either reported as a medical act or diagnosis in both the RAMQ database and the survey. Most visits related to a mental disorder were associated specifically with depression or anxiety. Individuals with mental disorder were found to consult general practitioners twice as often (12 visits annually) as individuals without 
mental disorder (6 visits annually). In the survey, the continuity of care provided by general practitioners was investigated (number of visits per year to a "family physician" for treatment of a mental disorder). Common mental disorder cases were seen on average nine times per year, and serious mental disorder six times.

General practitioners generally used their clinical intuition, experience, and the DSM-IV to detect and diagnose mental disorder. Standardized scales or questionnaires were used infrequently (reserved essentially for specific or complex cases). Occasionally, these instruments were used to persuade patients who did not recognize their disorder and shepherd them into the care process. Few general practitioners considered using these tools to monitor mental healthcare outcomes. Almost all general practitioners reported managing patients with common mental disorder on a continual basis and felt confident in adequately treating these cases. The situation was reversed for serious mental disorder; very few general practitioners mentioned treating them on a regular basis; generally, they did not felt confident enough to take them on. In general, basic treatment for mental disorder offered by general practitioners was medication and support therapy - very few used best-practice treatment guidelines. General practitioners who managed more patients with serious disorders shared the following profile: they had more training in mental health; they had practiced in psychiatric settings; they were practicing in community care centers (where multidisciplinary teams were available onsite, and general practitioners were paid on a salary basis); they practiced more in rural and semi-urban territories (where psychiatrists were less numerous). General practitioners also estimated that they managed, on a regular basis, $71 \%$ of the patients with common mental disorder who consulted them, as compared with $34 \%$ of individuals with serious mental disorder.

General practitioners were also found to practice mostly in solo (on an individual basis little collaboration from other medical or psychosocial professionals). They reported that they benefitted from few formal collaboration practices (for example, shared care) in the management of patients with mental disorder. Moreover, they believed the quality of the mental healthcare system to be quite poor; consequently, they supported reforms designed to enhance primary integrated care. Referral was the strategy they used most often in response to the diverse needs of patients with mental disorder. In their estimation, general practitioners referred $17 \%$ of their patients with common mental disorder to mental healthcare resources (including $31 \%$ of patients to psychologists in private practice; $20 \%$ to psychosocial professionals in community care centers; $13 \%$ to psychiatrists). They also referred $71 \%$ of patients with serious mental disorder (mainly to psychiatric facilities and emergency rooms). More than $50 \%$ of the general practitioners also reported that they had no contact (face-to-face or telephone interaction) with any one of the following mental healthcare resources: psychiatrists, community care centers, psychologists in private practice, the voluntary sector, or detox centers.

\subsection{Enabling and hindering factors in the management of patients with mental disorder}

Enabling factors in general practitioners' management of patients with mental disorder were as follows: (1) considerable interest in the management of mental disorder; (2) personal skills such as listening and empathy; (3) working in an interdisciplinary practice setting, especially community care centers (where general practitioners also are paid by salary or hourly fee); (4) high volume of patients with mental disorder with no complex or recursive profiles (allowing physicians to consolidate knowledge); (5) training in the treatment of 
mental disorder (academic settings and continuing education); (6) limited access to psychiatric care (which compels general practitioners to manage patients with mental disorder); and (7) patient rostering (encouraging continuity of care by general practitioners). Interprofessional collaboration with general practitioners was strengthened when: (1) general practitioners worked mainly in community care centers; (2) they had practiced or were currently practicing in psychiatric care facilities; (3) they have developed strong informal networks (that is, personal relationships with mental healthcare resources), thereby bypassing long waiting time and gaining prompt access to the formal mental healthcare network; (4) they were practicing in healthcare networks where shared care (or collaborative care) was developed, including evaluation liaison modules (the latter is a referral process to specialized mental disorder services that general practitioners can use, usually deployed through university-affiliated psychiatric facilities in Quebec).

Several hindering factors associated with general practitioners' management of mental disorder were found: (1) significant lack of mental healthcare resources in the Quebec healthcare system; (2) long waiting time for access to mental healthcare, especially psychiatric care (60 days' wait on average in Quebec) and psychotherapy at community care centers (where it is free of charge, covered by the public healthcare system); (3) insufficient knowledge of waiting time for access to services, which impedes care management; (4) limited psychotherapy sessions (either in community care centers (public system) or in the private system through insurance coverage); (5) great difficulty communicating with mental healthcare resources; (6) low availability of general practitioners given the shortage of family physicians in Quebec as healthcare demand increases; (7) inappropriate remuneration or incentives offered to general practitioners for the management of mental disorder (especially troublesome in this regard are fees for services, which fail to compensate for longer and frequent patient visits and also fail to take into account the importance of collaboration with mental healthcare resources which are not remunerated); (8) bureaucracy and inefficiency of referral and collaboration procedures; (9) instability of healthcare resources, especially the high turnover of professionals as Quebec undergoes healthcare reforms; (10) training that does not favor interprofessional collaboration; and (11) complexity of patient profiles and management of mental disorder (for example, the need to treat concomitant illnesses along with mental disorder; general practitioners' emotional involvement or investment in the care of patients with mental disorder; frequency of followups with insurance companies when patients take sick leave). Even though psychiatric access has been facilitated in some Quebec healthcare networks, general practitioners still deplore the absence of: stepped care when patients need it; continuous support from psychiatrists, especially when recommendations provided by psychiatrists to general practitioners do not lead to expected results or when patients' health does not warrant their transfer back to their general practitioner; psychiatric care in the evening and on weekends; and access to psychiatrists for semi-urgent cases (urgent cases were rapidly seen at emergency rooms).

\subsection{General practitioner strategies and recommendations to improve the management of mental disorders}

To bypass the negative impacts of mental disorder management on their practice, general practitioners have suggested the following strategies: optimizing their informal collaborative networks; plan longer and more numerous consultations ("one problem per 
consultation solution"), particularly at the beginning and the end of the day; reserve time slots for potential patient crises (or emergency situations), walk-in clinics being ideal for these situations; and provide self-referral to other, more appropriate practice settings for the treatment of mental disorder (as a result, general practitioners would see patients in varied settings, including community care centers, in accordance with the current trend of general practitioners working in several settings). Effective incentives for the management of mental disorder and maintenance of collaboration were also highlighted as desirable developments. General practitioners were all in favor of increasing access to psychiatrists and psychotherapy. The latter, especially cognitive behavioral therapists, associated with medication, stood out as a best-practice option in the management of common mental disorder. More intensive contact between general practitioners and psychosocial professionals, especially psychologists, was promoted in the form of brief reports or telephone follow-ups designed to clarify treatment objectives, propose approaches, and forecast the length of therapy. Shared care led by psychiatrists was also identified as a key strategy to strengthen the treatment of more complex cases of common mental disorder (for example, when medication or treatment does not work, recurrent cases, and crisis situations) or serious mental disorder. One monthly visit to the general practitioner and weekly telephone support from psychiatrists when needed were recommended. Training sessions every three months, involving case studies with various mental healthcare professionals (for example, psychologists and social workers), under the leadership of psychiatrists in local service networks was also highly recommended, as these were considered to foster knowledge on mental disorder and favor networking or the creation and maintenance of a community of practice among professionals.

General practitioners have also recommended the integration of nurses with sufficient experience in the treatment of mental disorder into their work settings. Nurses' role would be to prioritize patients to be seen, collect relevant information on patient profiles (for example, social support, life habits, medical record), offer psycho-education services (involving links with the family when appropriate), strengthen drug adherence, and provide case management for more complex mental disorder cases. Collaboration with social workers (rather than nurses) was preferred for the treatment of patients with serious mental disorder given these patients' need for rehabilitation and life-skill learning. According to general practitioners, the voluntary sector and detox centers should be further integrated into the primary care system; accordingly, mental healthcare teams in community care centers would coordinate patient care with these partners. The inclusion of diverse mental healthcare professionals in general practitioner settings was recommended as an initial reform in family medicine groups and network clinics, where rostering of patients exists and nurses are already on the payroll. The integration of mental healthcare professionals in general practitioner offices was perceived as a key issue for improving the management of mental disorder. This strategy would enhance the efficiency of the mental healthcare system, screening of patients, and prevention of mental disorder. It would lead to more appropriate responses to patient needs on an ongoing basis, thereby reducing hospitalization and emergency-room visits and favoring patient recovery. Finally, the integration of mental healthcare professionals was seen to be an appropriate solution to relieve the pressure on general practitioners with respect to patient follow-up and help to attenuate the shortage of family physicians (calling on mental healthcare professionals for cases of mental disorder would free up general practitioners and allow them to see an increasing number of new patients). 


\section{Discussion}

As mentioned above, general practitioners are consulted more frequently for mental disorder problems than other healthcare professionals (Heymans, 2005: Walters et al., 2008). According to the Canadian Community Health Survey (CCHS, Statistics Canada, 2002; Lesage et al., 2006), 5\% of the Quebec population aged over 18 consulted a general practitioner for a mental disorder problem (which is almost the same percentage in the United States; Vasiliadis et al., 2007). In the Quebec public register (RAMQ database), we found that figure to $15 \%$. The gap between the population survey $(5 \%)$ and the database $(15 \%)$ may be explained by an underestimation in the population survey of the number of patient visits to general practitioners for mental disorder problems and the high volume of patient visits to general practitioners for concurrent physical problems or conditions (for example, chronic problems or substance abuse) as reflected in the database. In addition, the figure of $15 \%$ includes mental disorder diagnoses and clinical acts; the latter showing an upward trend in recent years. This trend is interesting and parallels the increase in drug prescriptions in the recent years. There has been an upsurge in prescriptions in Quebec even in cases where there was no specific diagnosis of mental disorder (Conseil du médicament, 2011). In the United States, the annual incidence of antidepressant treatment increased from $2.2 \%$ in $1990-1992$ to $10.1 \%$ in $2001-2003$ (Mojtabai, 2008); in New Zealand, from $7.4 \%$ in 2004-2005 to 9.4\% in 2006-2007 (Exeter et al., 2009); in Italy, from 5.1\% in 2003 to $6.0 \%$ in 2004 (Trifiro et al., 2007); and in Quebec, from $8.1 \%$ in 1999 to $14.9 \%$ in 2009 (Conseil du médicament, 2011). Generally, it should be noted that there is no gold standard in the measurement of mental healthcare service use (surveys, database or administrative records are all used to gauge service utilization). Individuals with a mental illness may systematically under-or over-report their service use (Rhodes \& Fung, 2004); therefore, comparing results from different tools or strategies is of interest and value.

There are mixed findings with regard to general practitioners' preparation and confidence in taking on patients with common mental disorder (Bathgate et al., 2001; Krupinski \& Tiller, 2001). Similarly to our research, recent studies (Rockman et al., 2004; Wright et al., 2005; see also Fleury et al., 2009) show that general practitioners are comfortable treating most cases of common mental disorder, but experience difficulty treating personality disorders, eating disorders, substance-abuse disorders, and young patient with mental disorder. For substance abuse co-morbidity and some cases of refractory and recursive common mental disorder, general practitioners also expressed a need for psychiatric expertise for evaluation and diagnosis, medication follow-up, and specialized intervention: generally, these are the three reasons that are reported in the literature for referral to psychiatric services (Rockman et al., 2004). Some studies have cast doubt on the ability of general practitioners to diagnose and treat more complex forms of mental disorder, particularly major depression with suicidal tendency, schizophrenia, and bipolar disorder (Wright et al., 2005). In our research, few general practitioners managed patients with serious mental disorder on a consistent basis. A parallel random cohort study of 140 patients with serious mental disorder released from hospital 12 months before the survey and living in five of Quebec's administrative health regions (Fleury et al., 2010b) showed that $93 \%$ of patients were followed by a psychiatrist, $84 \%$ by a case manager, and only $50 \%$ by a general practitioner. There are many reasons explaining why only a minority of general practitioners manage patients with severe mental disorder. Such patients are deemed to be more difficult to treat and require more care, time, and frequent visits (Balanchandra et al., 2005; Kisely et al., 2006). Often, 
they have concurrent diagnoses (for example, substance abuse) and interrelated physical or social problems (Iacovides et al., 2008; Jones et al., 2008). General practitioners either consider these disorders too specialized for routine primary care, deeming their skills and experience inadequate for effective diagnosis and treatment, or they position themselves as complementary to specialized care, treating what are essentially physical problems (Lester et al., 2005; Lockhart, 2006). None of these findings suggest that general practitioners should be removed from the treatment equation for these patients. Patients with serious mental disorder are in great need of adequate physical care and mental health follow-up as they face higher risks of interrelated morbidity. Moreover, as psychiatric teams are generally located in urban settings, general practitioners are often the sole available source of care. This is the case in Quebec where almost half of the psychiatrists practice in the Montreal metropolitan area, and where in more remote regions, specialized care is scarce (Lafleur, 2003). Best practices for serious mental disorder management usually include more comprehensive care packages delivered by multidisciplinary teams on a longitudinal basis (Slade et al., 2005; Lester et al., 2005) . As a result, the care pathway for patients with serious mental disorders involves greater collaborative care (especially links between primary and specialized care), since it entails more frequent referrals.

However, general practitioners working in Quebec community care centers (paid by salary) perceived themselves as able to treat patients with more complex mental disorder. Previous studies (Geneau et al., 2007, 2008) have highlighted the key role played by community care centers (or multidisciplinary settings) in the treatment of complex cases involving both physical and mental illness, which are generally associated with dimmer prognoses. Family medicine groups and network clinics, promoting physician group practice and involving nurses, can also play a key role in the treatment of more complex mental healthcare cases. However, our study, similarly to others (Ministère de la Santé et des services sociaux du Québec, 2009a; 2009b), did not find evidence of this. Nurses with training in the treatment of mental disorder should be recruited, and targeted outcomes in mental health should be introduced.

Our findings show that general practitioners refer patients with mental disorder according to diagnosis, that is, common mental disorder or severe mental disorder, the former being less frequently referred. In fact, most patients with common mental disorder are treated by general practitioners, without significant referral to other mental healthcare providers. In the international literature (Valenstein et al., 1999; Younes et al., 2005; Grembowski et al., 2002), referral rates between general practitioners and mental healthcare resources range from 4 and $23 \%$ of patients with mental disorder. More considerable variations are reported for contacts, with 9 to $65 \%$ of general practitioners estimated to have some contact with mental healthcare providers (Craven \& Bland, 2006). Compared to contact (for example, shared-care initiatives, face-to-face or telephone follow-up), referral is difficult to interpret when gauging the effectiveness of clinical practice since it does not provide information regarding failures to refer and does not distinguish between useful and unnecessary referral. Patients may be harmed if referral occurs too late, and delays may make major treatment necessary in later stages. A large number of referrals also may be interpreted as patient transfers (Coulter, 1998). In the referral process, concurrent treatment may be parallel rather than collaborative. Patients may fail to follow through with referral, without their general practitioners' knowledge (Valenstein et al., 1999). In the Canadian Community Health Survey for instance, close to $50 \%$ of the population who saw a general practitioner for mental a disorder also concurrently used the services of another healthcare professional 
(Lesage et al., 2006) - this proportion is much higher than the figures reported by general practitioners (even if the number of patient from referral and contact are included). In a study conducted in a Montreal catchment area where 2,443 individuals were surveyed, 406 $(17 \%)$ experienced at least one mental disorder episode in the 12 months before their participation in the study. Among this subset, 212 (52\%) reported at least one episode of healthcare service use. Most participants consulted general practitioners (63\%), psychiatrists $(58 \%)$ and psychologists $(32 \%)$, and $20 \%$ consulted with at least four types of professionals (Fleury et al., in revision). In light of general practitioners' reports with respect to patient referral, these two studies raise serious questions regarding general practitioners' knowledge of the "parallel care" their patients seek.

For Rothman and Wagner (2003), non-physicians play a significant role in most successful treatments of chronic illness. Our research found that general practitioners mainly referred patients with common mental disorder to psychologists in private practice, followed by psychosocial resources in community care centers, and, finally, psychiatrists. The major role played by psychologists (or other well-trained psychosocial professionals) in treating patients with common mental disorder has been abundantly reported (Parslow \& Jorm, 2000; Grenier et al., 2008). General practitioners in our research recommended joint psychotherapy and medication for most of their patients with mental disorder, suggesting that they recognized the limited effectiveness of a pharmacology-only approach. Some patients also prefer psychotherapy instead of medication (van Rijswijk et al., 2009). Moreover, as already said, compliance to medication being generally poor in those patients (Conseil du Médicament, 2011; Seekles et al., 2009), there is a great need to reinforce psychoeducational or patient-centered approaches. Psychiatrists, also viewed as key partners, were essential to the management of more difficult cases of mental disorder and knowledge transfer. Similarly to other studies (van Rijswijk et al., 2009), general practitioners recommended a key role for nurses, but with some reservation. The serious shortage of nurses in the Quebec healthcare system (as in several other countries, WHO, 2006) would undoubtedly hamper efforts to foster their participation in mental healthcare. Contrary to other Canadian provinces and some other countries, mental healthcare nursing is not a recognized specialty in Quebec (Canadian Institute for Health Information, 2008, 2010). Moreover, the number of hours dedicated to mental healthcare training in nursing school is low (and has steadily been decreasing in recent years) (Ordre des infirmières et infirmiers $d u$ Québec, 2009). As a result, nurses in the province may not always be appropriately equipped to play an extensive role in primary mental healthcare.

In our research, as in the literature, different factors were found that may account for general practitioners' decision to treat patients with mental disorder: (1) environment (international trends, mental healthcare policies); (2) macro-organizational features and reforms (collaborative care, access to resources); (3) practice settings (remuneration by salary, internal professional collaboration, volume of patients with mental disorder); (4) general practitioners' individual characteristics (training and background in mental healthcare, informal networks, interests and confidence in treating mental disorder); and (5) patient management profiles (attitudes, illness severity, prognoses).

In efforts to improve primary care in Quebec, particularly regarding mental disorder, the following initiatives have been deployed: family medicine groups; network clinics; and shared care, including the consolidation of mental health psychosocial teams and introduction of single access points in community care centers within each local network. Single access points serve as a standardized and coordinated referral procedure to 
psychosocial services (patient self-referral or general practitioner referral) in all local networks, at community care centers (where psychosocial services are covered by the public system) or to psychiatric services in hospital settings, when patients require specialized care. Our results showed that the Quebec reform has not yet significantly improved the mental healthcare system, as quality of care was regarded to be quite poor and care collaboration as being severely underdeveloped. This state of affairs is due in part to the modest progress made in implementing current reforms (for example, very little development of shared care, understaffed psychosocial teams at community care centers, and inadequate operation of single access points). Findings of poor mental healthcare quality unfortunately are not specific to Quebec; numerous studies (Pawlenko, 2005; Nolan \& Badger, 2002) have found similar results in other countries; however, recent efforts in some countries, for example, the United Kingdom and Australia to bring about improvements in this regard have been noted (Hickie \& Groom, 2002; Lester et al., 2004). Repeated mention of insufficient collaboration among providers, particularly psychiatrists and general practitioners, can be found in the literature (Bambling et al, 2007; Cunningham, 2009). Upshur and Weinreb (2008) have indicated that partial implementation of shared-care initiatives does not usually produce substantive outcomes. Key elements for development of effective shared care, as per the literature (Kringos et al., 2010; Upshur \& Weinreb, 2008), include: the development of electronic medical records; physician leadership; incentives for inter-professional collaboration and management of complex patient profiles; team vision; recognition of diversified expertise requirements; absence of hierarchical structures among professionals; adequate space and locations; effective management and clinical skills; strong commitment to innovation and patient empowerment; and established clinical relationships. To improve the quality of mental healthcare services, other recurring issues to pay attention to are: long waiting times for psychiatric care or psychotherapy at no charge; limited primary-care team practice; general practitioners' limited training or experience with effective team practice (Rothman \& Wagner, 2003); inappropriate modes of remuneration; and lack of financial incentives for general practitioners to manage patients with mental disorder (Collins, 2006; Morden et al., 2009). General practitioners' busy schedules and the competing demands of other patients are other contributing factors (Starfield, 1998; Craven \& Bland, 2006). The historical separation between psychiatry and primary care (Crews et al., 1998) may also explain general practitioners' reluctance to take on patients with mental disorder, especially among those who may consider hospital psychiatric teams to be more appropriate. In addition, the length of visits, essentially designed for general practitioners to prescribe medication and provide quick support therapy, was found to be too brief to permit optimal management of mental disorder. Consequently, in the light of the foregoing, implementing strategies to enhance general practitioners' management of mental disorder represents a considerable challenge.

\section{Conclusion}

On the whole, our research studies found that general practitioners welcomed opportunities to manage patients with common mental disorder; however, they also faced a number of obstacles, including: healthcare system fragmentation; lack of communication, resources, and clinical tools; the prevalence of solo practice; and unsuitable modes of payment. In Quebec, as in most other jurisdictions, reforms are under way, but best practices such as patient self-management, stepped-care therapy, and shared care are as yet underdeveloped. 
General practitioners worked mainly in solo practice and relied on their clinical intuition with little clinical or collaborative support. Psychosocial resources, such as cognitive behavioral therapy, are not sufficiently widespread, which too often compelled general practitioners to turn to pharmacological solutions as the only affordable option for patients. In light of current reforms and best-practice recommendations, our research advocates, as a stepped-care approach to system change, increased access to psychologists and psychiatrists as in other countries (for example, the United Kingdom and Australia) in efforts to implement further biopsychosocial modes of treatment and strengthen collaborative care. Development of a network of general practitioners in multidisciplinary settings with more specialized knowledge of mental disorder would prove beneficial in the treatment of more complex cases. Specialized resources for the treatment of substance abuse (given the incidence of concomitant disorders) and greater participation by the voluntary sector also represent desirable developments. In addition, rostering of patients and salary-based or hourly-fee compensation should be promoted. Continuing education and case discussion in local networks with psychiatrists and multidisciplinary resources are also recommended as they favor skill and network development, respectively. Government policy, implementation incentives, and support mechanisms must drive reforms, enabling general practitioners to play a significant role in the management of mental disorders and bolstering integrated biopsychosocial approaches. Finally, a culture of collaboration has to be encouraged as comprehensive services and continuity of care are key recovery factors of patients with mental disorder. Collaborative care, an extended role for psychosocial resources, and more efficient mental primary care organization should lead to expanded caseloads for general practitioners and better access to services for patients with mental disorder.

\section{Acknowledgment}

The research was funded by the Canadian Institute of Health Research (CIHR), Fonds de la recherche en santé $d u$ Québec (FRSQ) and other decision-making partners. We would like to thank all the grant agencies, partners, and general practitioners who took part in the research project. In addition, we would like to underscore the contribution of our project coresearchers: Drs Jacques Tremblay, Jean-Marie Bamvita, Lambert Farand, Denise Aubé, Alain Lesage, and Armelle Imboua.

\section{References}

Albert, M., Becker, T., McCrone P. \& Thornicroft, G. (1998). Social networks and mental health service utilisation. A literature review. International Journal of Social Psychiatry, Vol. 44, No. 4, (Winter 1998), pp. 248-266, ISSN 0020-7640

Alegria, M., Bijl, R.V., Lin, E., Walters, E.E. \& Kessler, R.C. (2000). Income differences in persons seeking outpatient treatment for mental disorders: a comparison of the United States with Ontario and the Netherlands. Archives of General Psychiatry, Vol. 57, No. 4, (April 2000), pp. 383-391, ISSN 0003-990X

Bachrach, L.L. (1996). Psychosocial rehabilitation and psychiatry: what are the boundaries? Canadian Journal of Psychiatry, Vol. 41, No. 1, (February 1996), pp. 28-35, ISSN 07067437 
Balanchandra, K., Sharma, V., Dozois, D. \& Bhayana, B. (2005). How bipolar disorders are managed in family practice: self-assessment survey. Canadian Family Physician, Vol. 51, No. 4, (April 2005), pp. 534-535, ISSN 0008-350X

Bambling, M., Kavanagh D., Lewis G., King, R., King, D., Shurk, H., Turpin, M., Gallois, C. \& Bartlett, H. (2007). Challenges faced by general practitioners and allied mental health services in providing mental health services in rural Queensland. Australian Journal of Rural Health, Vol. 15, No. 2, (April 2007), pp. 126-130, ISSN 1038-5282

Bathgate, D., Bermingham, B., Curtis, D. \& Romans, S. (2001). The view of Otago urban and rural General Practitioners on mental health services. New Zealand Medical Journal, No. 114, No. 1134, (June 2001), pp. 289-291, ISSN 0028-8446

Bebbington, P., Meltzer, H., Brugha, T.S., Farrell, M., Jenkins, R., Ceresa, C. \& Lewis, G. (2000). Unequal access and unmet need: neurotic disorders and the use of primary care services. Psychological Medicine, Vol. 30, No. 1-2, (February-May 2000), pp. 1359-1367, ISSN 0033-2917

Bergman, J.S. (2007). Primary Health Care Transition Fund. Evaluation and evidence. Health Canada, Ottawa, Canada

Bilsker, D. (2010). Supported self-management: Maximizing the impact of primary mental heath care. Quintessence, Vol. 2, No. 1 (January 2010). Available from: www.qualaxia.org/mental-health-information/quintessence.php?lg=en

Bodenheimer, T., Wagner, E.H. \& Grumbach, K. (2002). Improving primary care for patients with chronic illness. Journal of American Medical Association, Vol. 288, No. 14, (October 2002), pp. 1775-1779, ISSN 0098-7484

Bonin, J.P., Fournier, L. \& Blais, R. (2007). Predictors of mental health service utilization by people using resources for homeless people in Canada. Psychiatric Services, Vol. 58, No. 7, (July 2007), pp. 936-941, ISSN 1075-2730

Bosco, C. (2005). Health human resources in collaborative mental health care. A discussion on overcoming the human resource barriers to implementing collaborative mental health care in Canada. Canadian Collaborative Mental Health Initiative, ISBN 1-896014-82-8, Mississauga, Ontario.

Bourgueil, Y., Marek, A. \& Mousquès, J. (2007). Médecine de groupe en soins primaires dans six pays européens, en Ontario et au Québec : quels enseignements pour la France? Questions d'économie de la santé, No. 127, (November 2007), pp. 1-8, ISSN 1238-4769

Bower, P. \& Gilbody, S. (2005). Stepped care in psychological therapies: access, effectiveness and efficiency. Narrative literature review. British Journal of Psychiatry, No. 186, (January 2005), pp. 11-17, ISSN 0007-1250

Bower, P. (2002). Primary care mental health workers: models of working and evidence of effectiveness. British Journal of General Practice, Vol. 52, No. 484, (November 2002), pp. 926-933, ISSN 0960-1643

Breier, A., Schreiber, J.L., Dyer, J. \& Pickar, D. (1991). National Institute of Mental Health longitudinal study of chronic schizophrenia. Prognosis and predictors of outcome. Archives of General Psychiatry, Vol. 48, No. 3, (March 1991), pp. 239-248, ISSN 0003990X

Canadian Institute for Health Information. (2010). Infirmières réglementées: tendance canadienne, de 2005 à 2009. Canadian Institute for Health Information, ISBN 978-155465-828-2, Ottawa, Canada 
Canadian Institute for Health Information (2008). Les dispensateurs de soins de santé au Canada, de 1997 à 2006 - Guide de référence. Canadian Institute for Health Information, ISBN 978-1-55465-318-8, Ottawa, Canada

Carr, V.J., Johnston, P.J., Lewin, T.J., Rajkumar, S., Carter, G.L. \& Issakidis, C. (2003). Patterns of service use among persons with schizophrenia and other psychotic disorders. Psychiatric Services, Vol. 54, No. 2, (February 2003), pp. 226-235, ISSN 1075-2730

Casper, E.S. \& Donaldson, B. (1990). Subgroups in the population of frequent users of inpatient services. Hospital \& Community Psychiatry, Vol. 41, No. 2, (February 1990), pp. 189-191, ISSN 0022-1597

Chomienne, M.H., Grenier, J., Gaboury, I., Hogg, W., Ritchie, P. \& Farmova-Haynes, E. (2010). Family doctors and psychologists working together: doctor's and patients' perspectives. Journal of Evaluation in Clinical Practice, Vol. 17, No. 2, (April 2010), pp. 282-287, ISSN 1356-1294

Clark, D.M., Layard, R., Smithies, R., Richards, D.A., Suckling, R. \& Wright, B. (2009). Improving access to psychological therapy: Initial evaluation of two UK demonstrations sites. Behaviour and Research Therapy, Vol. 43, No. 3, (November 2009), pp. 910-920, ISSN 0005-7967

College of Family Physicians of Canada (2009). Patient-centred primary care in Canada: Bring it on home. College of Family Physician of Canada, Mississauga, Ontario

College of Family Physicians of Canada (2008). Soutenir les effectifs futurs en médecine familiale au Canada. En fait-on assez aujourd'hui pour se préparer pour demain? College of Family Physician of Canada, Mississauga, Ontario

College of Family Physicians of Canada (2007). National Physician Survey. Available from: www.nationalphysiciansurvey.ca/nps/2007_Survey/2007nps-e.asp

College of Family Physicians of Canada (2004). National Physician Survey. Available from: www.nationalphysiciansurvey.ca/nps/2004_Survey/2004results-e.asp

Collins, K. A., Wolfe, V.V., Fisman, S., DePace, J. \& Steele, M. (2006). Managing depression in primary care: community survey. Canadian Family Physican, Vol. 52, No. 7, (July 2006), pp. 878-879, ISSN 0008-350X

Commissaire à la Santé et au Bien-être (2010). Rapport d'appréciation de la performance du système de santé et de services sociaux 2010 : Adopter une approche intégrée de prévention et de gestion des maladies chroniques: recommandations, enjeux et implication. Gouvernement du Québec, ISBN 978-2-550-58277-4, Québec, Québec

Commissaire à la Santé et au Bien-être (2009). L'expérience de soins des personnes présentant les plus grands besoins de santé: le Québec comparé. Résultats de l'enquête internationale sur les politiques de santé du Commonwealth Fund de 2008. Gouvernement du Québec, ISBN 978-2-550-57271-8, Québec, Québec

Conseil du Médicament. (2011). Portrait de l'usage des antidépresseurs chez les adultes assurés par le régime d'assurance médicaments du Québec. Gouvernement du Québec, ISBN 978-2-550-60457-0, Québec, Québec

Coulter, A. (1998). Managing demand at the interface between primary and secondary care. British Medical Journal, Vol. 316, No. 7149, (June 1998), pp. 1974-1976, ISSN 09598138 
Craven, M. \& Bland R. (2006). Better practices in collaborative mental health care: an analysis of the evidence base. Canadian Journal of Psychiatry, Vol 51, No. 6, (May 2006) pp. 7s-72s, ISSN 0706-7437

Crews, C., Batal, H., Elasy, T., Casper, E. \& Mehler, P.S. (1998). Primary care for those with severe and persistent mental illness. Western Journal of Medicine, Vol. 169, No. 4, (October 1998), pp. 245-250, ISSN 0093-0415

Cruickshank, J. (2010). The patient-centered medical home approach to improve dyslipidemia outcomes. Journal of the American Osteopathic Association, Vol. 110, No. 4, Suppl 5, (April 2010), eS3-5, ISSN 0098-6151

Cunningham, P.J. (2009). Beyond parity: primary care physicians' perspectives on access to mental health care. Health Affairs, Vol. 28, No. 3, (May-June 2009), pp. w490-501, ISSN 1544-5208

Demyttenaere, K., Bruffaerts, R., Posada-Villa, J., Gasquet, I., Kovess, V., Lepine, J.P., Angermeyer, M.C., Bernet, S., de Girolamo, G., Morosini, P., Polidori, G., Kikkawa, T., Kawakami, N., Ono, Y., Takeshima, T., Uda, H., Karam, E.G, Fayyad, J.A., Karam, A.N., Mneimneh, Z.N., Medina-Mora, M.E., Borges, G., Lara, C., de Graaf, R., Omel, J., Gureje, O., Shen, Y., Huang, Y., Zhang, M., Alonso, J., Haro, J.M., Vilagut, G., Bromet, E.J., Gluzman, S., Webb, C., Kessler, R.C., Merikangas, K.R., Anthony, J.C., Von Korff, M.R., Wang, P.S., Brugha, T.S., Aguilar-Gaxiola, S., Lee, S., Heeringa, S., Pennell, B.E., Zalavsky, A.M., Ustun, T.B., Chatterji, S. \& WHO World Mental Heath Survey Consortium (2004). Prevalence, severity, and unmet need for treatment of mental disorders in the World Health Organization World Mental Health Surveys, Journal of the American Medical Association, Vol. 291, No. 21, (June 2004), pp. 2581-2590, ISSN 0098-7484

Desjardins, Y. (2011). Strengthening primary care: A priority. Qmentum Quarterly: Quality in Health Care, Vol. 3, No. 1, (May 2011), pp. 10-12, 1918-039X

Dorr, D., Bonner, L.M., Cohen, A.N., Shoai, R.S., Perrin, R., Chaney, E. \& Young, A.S. (2007). Informatics systems to promote improved care for chronic illness: A literature review. Journal of the American Medical Informatics Association, Vol. 14, No. 2, (MarchApril 2007), pp. 156-163, ISSN 1067-5027

Exeter, D., Robinson, E. \& Wheeler, A. (2009). Antidepressant dispensing trends in New Zealand between 2004 and 2007. Australian and New Zealand Journal of Psychiatry, Vol. 43, No. 12, (December 2009), pp. 1131-1140, ISSN 0004-8674

Fervers, B., Burgers, J., Haugh, M.C., Latreille, J., Mlika-Cabanne, N., Paquet, L., Coulombe, M., Poirier, M. \& Burnand, B. (2006). Adaptation of clinical guidelines: literature review and proposition for a framework and procedure. International Journal for Quality in Health Care, Vol. 18, No. 3, (June 2006), pp. 167-1776, ISSN 1353-4505

Fitzpatrick, N.K., Shah, S., Walker, N., Nourmand, S., Tyrer, P.J., Barnes, T.R., Higgitt, A. \& Hemingway, H. (2004). The determinants and effect of shared care on patient outcomes and psychiatric admissions - an inner city primary care cohort study. Social Psychiatry and Psychiatric Epidemiology, Vol. 39, No. 2, (February 2004), pp. 154-163, ISSN 0933-7954

Fleury, M.-J., Grenier, G., Bamvita, J.M., Perreault, M. \& Caron, J. (Revision). Determinants of the utilization of diversified types of professionals for mental health reasons in a Montreal catchment area. Community Mental Health Journal, ISSN 1573-2789 
Fleury, M.-J., Grenier, G., Bamvita, J.M., Perreault, M. \& Caron, J. (2011). Determinants associated with the utilization of primary and specialized mental health services. Psychiatric Quarterly. (May 2011), [Epub ahead of print], ISSN 1573-6709

Fleury, M.-J., Bamvita, J. M., Farand, L., Aubé, D., Fournier, L. \& Lesage, A. (2010a). GP group profiles and involvement in mental health care. Journal of Evaluation in Clinical Practice. (November 2010), [Epub ahead of print], ISSN 1365-2753

Fleury, M.-J., Grenier, G., Bamvita, J.-M. \& Caron, J. (2010b). Professional service utilization among patients with severe mental disorders. BMC Health Services Research, Vol. 10, (May 2010), p. 141, ISSN 1472-6963

Fleury M.-J., Bamvita, J.M. \& Tremblay J. (2009). Variables associated with general practitioners taking on serious mental disorder patients. BMC Family Practice, Vol. 10, No. 1, (June 2009), pp. 41, ISSN 1471-2296

Fleury, M.-J., Bamvita, J.M., Farand, L. \& Tremblay, J. (2008). Variables associated with general practitioners taking on patients with common mental disorders. Mental Health in Family Medicine, Vol. 5, No. 3, (September 2008), pp. 149-160, ISSN 1756-834X

Fleury, M.-J. (2006). Integrated Service Networks: The Quebec Case. Health Services Management Research, Vol. 19, No. 3, (August 2006), pp. 153-165, ISSN 0951-4848

Fontaine, P., Ross, S.E., Zink, T. \& Schilling, L.M. (2010). Systematic review of health information exchange in primary care practices. Journal of the American Board of Family Medicine, Vol. 23, No. 5, (September-October 2010), pp. 665-670, ISSN 15572625

Fournier, L., Aubé, D., Roberge, P., Lessard, L., Duhoux, A., Caulet, M. \& Poirier, L.R. (2007). Vers une première ligne forte en santé mentale: Messages clés de la littérature scientifique, Institut national de santé publique du Québec, Québec, Canada

Gask, L., Rogers, A., Campbell, S. \& Sheaff, R. (2008). Beyond the Limits of Clinical Governance? The Case of Mental Health in English Primary Care. BMC Health Services Research, Vol. 8, No. 63, (March 2008), pp. 1-10, ISSN 1472-6963

Geneau, R., Lehoux, P., Pineault, R. \& Lamarche, P. (2008). Understanding the work of general practitioners: a social science perspective on the context of medical decision making in primary care. BMC Family Practice, Vol. 9, (February), p. 12, ISSN 14712296

Geneau, R., Lehoux, P., Pineault, R. \& Lamarche, P.A. (2007). Primary care practice a la carte among GPs: using organizational diversity to increase job satisfaction. Family Practice, Vol. 24, No. 2, (April 2007), pp. 138-144, ISSN 0263-2136

Government of Canada (2006). The Human Face of Mental Health and Mental Illness in Canada. Public Works and Government Services, Ottawa, Canada, ISBN 0-662-72356-2

Grembowski, D., Martin, D. \& Patrick, D.L., Diehr, P. Katon, W., Williams, B., Engelberg, R., Novak, L., Dickstein, D., Devo, R. \& Goldberg, H.I. Managed Care, Access to mental health specialists, and outcomes among primary care patients with depressive symptoms. Journal of General Internal Medicine Subscribers, Vol. 17, No. 4, (April 2002), pp. 258-269, ISSN 1535-1497

Grenier, J., Chomienne, M.H., Gaboury, I., Ritchie, P. \& Hogg, W. (2008). Collaboration between family physicians and psychologists: what do family physicians know about psychologists' work? Canadian Family Physician, Vol. 54, No. 2, (February 2008), pp. 232-233, ISSN 0008-350X 
Hakkaart-van Roijen, L., van Straten, A., Maiwenn, A. Rutten, F. \& Donker, M. (2006). Costutility of brief psychological treatment for depression and anxiety. British Journal of Psychiatry, Vol. 188, No. 4, (April 2006), pp. 323-329, ISSN 0007-1250

Haggerty, J., Pineault, R., Beaulieu, M.D., Brunelle, Y., Goulet, F., Rodrigue, J. \& Gauthier, J. (2004). Continuité et accessibilité des soins de première ligne au Québec: barrières et facteurs facilitants. Fondation canadienne de la recherche sur les services de santé (FCRSS), ISBN 2-9807566-6-0, Ottawa, Canada

Hansson, L., Vinding, H.R., Mackeprang, T., Sourander, A., Werderlin, G., Bengtsson-Tops, A., Bjarnason, O., Dybbro, J., Nilsson, L., Sandlund, M., Sorgaard, K. \& Middelboe, T. (2001). Comparison of key worker and patient assessment of needs in schizophrenic patients living in the community: a Nordic multicentre study. Acta Psychiatrica Scandinavica, Vol. 103, No. 1, (January 2001), pp. 45-51, ISSN 0001-690X

Hatzenbuehler, M.L., Keyes, K.M., Narrow, W.E., Grant, B.F. \& Hasin, D.S. (2008). Racial/ethnic disparities in service utilization for individuals with co-occurring mental health and substance use disorders in the general population: results from the epidemiological survey on alcohol and related conditions. Journal of Clinical Psychiatry, Vol. 69, No. 7, (July 2008), pp. 1112-1121, ISSN 0160-6689

Hendryx, M.S. \& Ahern, M.M. (2001). Access to mental health services and health sector social capital. Administration and Policy in Mental Health, Vol. 28, No. 3, (January 2001), pp. 205-217, ISSN 0894-587X

Heymans, I. (2005). Argumentaire pour un système de santé fondé sur les soins de santé primaires et pour le soutien au développement de centres de santé intégrés. Fédération des maisons médicales et des collectifs de santé francophones, Vereniging van Wijkgezondheidscentra.

Hickie, I. \& Groom, G. (2002). Primary care-led mental health service refom: an outline of the better outcomes in mental health care initiatives. Australasian Psychiatry, Vol. 10, No. 4. (December 2002), pp. 376-382, ISSN 1440-1665

Howard, K.I., Cornille, T.A., Lyons, J.S., Vessey, J.T., Lueger, R.J. \& Saunders, S.M. (1996). Patterns of Mental Health Service Utilization. Archives of General Psychiatry, Vol. 53, No. 8, (August 1996), pp. 696-703, ISSN 0003-990X

Howell, C., Marshall, C., Opolski, M. \& Newbury, W. (2008). Management of recurrent depression. Australian Family Physician, Vol. 37, No. 9, (September 2008), pp. 704708, ISSN 0300-8495

Iacovides, A. \& Siamouli, M. (2008). Comorbid mental and somatic disorders: an epidemiological perspective. Current Opinion in Psychiatry, Vol. 21, No. 4, (July 2008), pp. 417-421, ISSN 0951-7367

Jones, B.J., Gallagher, B.J. 3rd, Pisa, A.M. \& McFalls, J.A. jr (2008). Social class, family history and type of schizophrenia. Psychiatry Research, Vol. 159, No. 1-2, (May 2008), pp. 127-132, ISSN 0165-1781

Jones, D.R., Macias, C., Barreira, P.J., Fisher, W.H., Hargreaves, W.A. \& Harding, C.M. (2004). Prevalence, severity, and co-occurence of chronic physical health problems of persons with serious mental illness. Psychiatric Services, Vol. 55, No. 11, (November 2004), pp. 1250-1257, ISSN 1075-2730

Joska, J. \& Flisher, A.J. (2005). The assessment of need for mental health services. Social Psychiatry and Psychiatric Epidemiology, Vol. 40, No. 7, (July 2005), pp. 529-539, ISSN 0933-7954 
Kates, N., Mazowita, G., Lemire, F., Jayabarathan, A., Bland, R., Selby, P., Isomura, T., Craven, M. Gervais, M. \& Audet, D. (2011). The evolution of collaborative mental health care in Canada: A shared vision for the future. Canadian Journal of Psychiatry, Vol. 56, No. 5, Suppl. 10, (May 2011), pp. 1-10, ISSN 0706-7437

Kates, N., Craven, M., Bishop, J., Clinton, T., Kraftcheck, D., Leclair, K., Leverette, J., Nash, L. \& Turner, T. (1997). Shared mental health care in Canada. Canadian Journal of Psychiatry, Vol. 42, No 38, Suppl. 12 (November), pp. 877-888, ISSN 0706-7437

Katon, W., Lin, E.H. \& Kroenke, K. (2007). The association of depression and anxiety with medical symptom burden in patients with chronic medical illness. General Hospital Psychiatry, Vol. 29, No. 2, (March-April 2007), pp. 147-155, ISSN 0163-8343

Katz, A., Glazier, R.H. \& Vijayaraghavan, J. (2009). The health and economic consequences of achieving a high-quality primary healthcare system in Canada. Applying what works in Canada closing the Gap. June 26 2011, Available from:

www.chsrf.ca/Libraries/Primary_Healthcare/11498_PHC_Katz_ENG_FINAL.sflb. ashx

Kent, S., Fogarty M. \& Yellowlees, P. (1995) A review of studies of heavy users of psychiatric services. Psychiatric Services, Vol. 46, No. 12, (December 1995), pp. 1247-1253, ISSN 1075-2730

Kent, S. \& Yellowlees, P. (1995). The relationship between social factors and frequent use of psychiatric services. Australian and New Zealand Journal of Psychiatry, Vol. 29, No. 3, (September 1995), pp. 403-408, ISSN 0004-8674

Kessler, R.C., Ruscio, A.M., Shear, K. \& Wittchen, H.U. (2010). Epidemiology of anxiety disorders. Current Topics in Behavioral Neurosciences, Vol. 2 (2010), pp. 21-35, ISSN 1866-3370

Kessler, R.C., Chiu, W.T., Demler, O. \& Walters, E.E. (2005). Prevalence, severity and comorbidity of 12-Month disorders in the National Comorbidity Survey Replication. Archives of General Psychiatry, Vol. 62, No. 6, (June 2005), pp. 617-627, ISSN 0003-990X

Kessler, R.C., Berglund, P.A., Bruce, M.L., Koch, J.R., Laska, E.M., Leaf, P.J., Mandersheid, R.W., Rosenheck, R.A., Walters, E.E. \& Wang, P.S. (2001). The prevalence and correlates of untreated serious mental illness. Health Services Research, Vol. 36, No. 6 Pt. 1, (December 2001), pp. 987-1007, ISSN 0017-9124

Keyes, K.M., Hatzenbuehler, M.L., Alberti, P., Narrow, W.E., Grant, B.F. \& Hasin, D.S. (2008). Service utilization differences for Axis I psychiatric and substance use disorders between white and black adults. Psychiatric Services, Vol. 59, No. 8 (August 2008), pp. 893-901, ISSN 1075-2730

Khan, S. C., McIntosh, C., Sanmartin, C., Watson, D., \& Leeb, K. (2008). Primary Health Care Teams and their impact on processes and outcomes of care. Statistics Canada. Health Research Working Paper Series. Available from: www.statcan.gc.ca/pub/82622x/82-622-x2008002-eng.htm

Kirby, M. J. L. (2006). Out of the Shadows at Last (Report). The Senate of Canada, Ottawa, Canada, June 27 2011. Available from:

www.parl.gc.ca/Content/SEN/Committee/391/soci/rep/pdf/rep02may06part1e.pdf 
Kisely, S. \& Campbell, L.A. (2007). Taking consultation-liaison psychiatry into primary care. International Journal of Psychiatry in Medicine, Vol. 37, No. 4, pp. 383-391, ISSN 00912174

Kisely, S., Duerden, D., Shaddick, S. \& Jayabarathan, A. (2006). Collaboration between primary care and psychiatric services: does it help family physicians? Canadian Family Physician, Vol. 52, (July 2006), pp. 876-877, ISSN 0008-350X

Korkeila, J.A., Lehtinen, V., Tuori, T. \& Helenius, H. (1998). Frequently hospitalised psychiatric patients: a study of predictive factors. Social Psychiatric and Psychiatric Epidemiology, Vol. 33, No. 11, (November 1998), pp. 528-534, ISSN 0933-7954

Kringos, D.S., Boerma, W.G., Hutchinson, A., van der Zee, J. \& Groenewegen, P.P. (2010). The breadth of primary care: a systematic literature review of its core dimensions. BMC Health Services Research, Vol. 10, (March 2010), pp. 65, ISSN 1472-6963

Krupinski, J. \& Tiller, J.W. (2001). The identification and treatment of depression by general practitioners. Australian and New Zealand Journal of Psychiatry, Vol. 35, No. 6, (December 2001), pp. 827-832, ISSN 0004-8674

Lafleur, P-A. (2003). Le métier de psychiatre au Québec. L'information psychiatrique. Vol. 79, No. 6, (June 2003), pp. 503-510, ISSN 0020-0204

Layard, R., Clark, D., Knapp, M. \& Mayraz (2007). Cost-benefit analysis of psychological therapy. National Institute Economic Review, No. 2002, (October 2007), pp. 90-98, ISSN 0027-9501

Leaf, P.J., Livingston, M.M., Tischler, G.L., Weissman, M.M., Holzer, C.E. 3rd \& Myers, J.K. (1985). Contact with health professionals for the treatment of psychiatric and emotional problems. Medical Care, Vol. 23, No. 12, (December 1985), pp. 1322-1337, ISSN 0025-7079

Lemming, M.R. \& Calsyn, R.J. (2004). Utility of the behavioral model in predicting service utilization by individuals suffering from severe mental illness and homelessness. Community Mental Health Journal, Vol. 40, No. 4, (August 2004), pp. 347-364, ISSN 0010-3853

Lesage, A., Vasiliadis, H.-M., Gagné, M.-A., Dudgeon, S., Kasman, N. \& Hay, C. (2006). Prevalence of mental illness and related service utilization in Canada: an analysis of the Canadian Community Health Survey. Health Canada's Primary Health Care Transition Fund, ISBN 1-869014-84-4, Mississauga: Ontario

Lester, H., Tritter, J.Q. \& Sorohan, H. (2005). Patients' and health professionals' views on primary care for people with serious mental illness: focus group study. British Medical Journal, Vol. 330, No. 7500, (May 2005), pp. 1122-1126, ISSN 0959-8138

Lester, H., Glasby, J. \& Tylee, A. (2004). Integrated primary mental health care: threat or opportunity in the new NHS? British Journal of General Practice, Vol. 54, No. 501, (April 2004), pp. 285-291, ISSN 0960-1643

Lloyd, K.R., Jenkins, R. \& Mann, A. (1996). Long-term outcome of patients with neurotic illness in general practice. British Medical Journal, Vol. 313, No. 7048, (July 1996), pp. 26-28, ISSN 0959-8138

Lockhart C. (2006). Collaboration and referral practices of general practitioners and community mental health workers in rural and remote Australia. Australian Journal of Rural Health, Vol. 14, No. 1, (February 2006), pp. 29-32, ISSN 1038-5282 
McAvoy, B.R. \& Coster, G.D. (2005). General practice and the New Zealand reforms- lessons for Australia? Australia and New Zealand Health Policy, Vol. 2, (November 2005), pp. 26, ISSN 1743-8462

Middelboe, T., Mackeprang, T., Hansson, L., Werdelin, G., Karlsson, H., Bjarnason, O., Bengtsson-Tops, Dybbro, J., Nilsson, L.L., Sandlund, M. \& Sorgaard, K.W. (2001). The Nordic study on schizophrenic patients living in the community. Subjective needs and perceived help. European Psychiatry, Vol. 16, No. 4, (June 2001), pp. 207214, ISSN 0924-9338

Ministère de la Santé et des Services Sociaux du Québec (2009a). Évaluation de l'implantation et des effets des premiers groupes de médecine de famille au Québec. Gouvernement du Québec, ISBN 978-550-55493-4, Québec, Québec

Ministère de la Santé et des Services Sociaux du Québec (2009b). Sondage auprès des infirmières des Groupes de médecins de famille du Québec - 2007-2008. Gouvernement du Québec, Québec, Québec

Ministère de la Santé et des Services Sociaux du Québec (2006). Plan d'action en santé mentale 2005-2010 - La force des liens. Ministère de la Santé et des Services sociaux, ISBN- 13 : 978-2-550-47927-7, Québec, Québec

Mojtabai, R. (2008). Increase in antidepressant medication in the US adult population between 1990 and 2003. Psychotherapy and Psychosomatics, Vol. 77, No. 2 (January), pp. 83-92, ISSN 0033-3190

Mojtabai, R., Olfson, M. \& Mechanic, D. (2002). Perceived need and help-seeking in adults with mood, anxiety, or substance use disorders. Archives of General Psychiatry, Vol. 59, No. 1, (January 2002), pp. 77-84, ISSN 0003-990X

Morden, N. E., Mistler, L.A., Weeks, W.B. \& Bartels, S.J. (2009). Health care for patients with serious mental illness: family medicine's role. Journal of the American Board of Family Medicine, Vol. 22, No. 2, (March-April 2009), pp. 187-195, ISSN 1557-2625

Moulding, R., Grenier, J., Blashki, G., Ritchie, P., Pirkis, J. \& Chomienne, M.H. (2009). Integrating psychologists into the Canadian health care system: the example of Australia. Canadian Journal of Public Health, Vol. 100, No. 2, (March-April 2009), pp. 145-147, ISSN 0008-4263

Mueser, K.T. \& McGurk, S.R. (2004). Schizophrenia. Lancet, Vol. 363, No. 9426, (June 2004), pp. 2063-2072, ISSN 1745-1701

Mykletun, A., Knudsen, A.K., Tangen, T. \& Overland, S. (2010). General practitioners' opinions on how to improve treatment of mental disorders in primary health care. Interviews with one hundred Norwegian general practitioners. BMC Health Services Research, Vol. 10, (February 2010), pp. 35, ISSN 1472-6963

Myhr, G. \& Payne, K. (2006). Cost-effectiveness of cognitive-behavioural therapy for mental disorders: Implications for public health care funding policy in Canada. Canadian Journal of Psychiatry, Vol. 51, No. 10, (September 2006), pp. 662-670, ISSN 0706-7437

Nabalamba, A. \& Millar, W.J. (2007). Going to the doctor. Health Reports, Vol. 18, No.1, (February 2007), pp. 23-35, ISSN 0840-6529

Narrow, W.E., Regier, D.A., Norquist, G., Rae, D.S., Kennedy, C. \& Arons, B. (2000). Mental health service use by Americans with severe mental illnesses. Social Psychiatry and Psychiatric Epidemiology, Vol. 35, No. 4, (April 2000), pp. 147-155, ISSN 0933-7954 
Nelson, G. (2006). Mental Health Policy in Canada. In Canadian Social Policy: Issues and Perspectives (4th ed), Westhues, A. (Ed.), pp. 245-266, Wilfrid Laurier University Press, ISBN 0889204055, Waterloo, Ontario

Nolan, P. \& Badger, F. (Eds.) (2002). Promoting collaboration in primary mental health care, Nelson Thormes, ISBN 0-7487-5874-7, Cheltenham, United Kingdom

Olfson, M., Marcus, S.C., Druss, B. \& Pincus, H.A. (2002). National trends in the use of outpatient psychotherapy. American Journal of Psychiatry, Vol. 159, No. 11 (November 2002), pp. 1914-1920, ISSN 0002-953X

Ordre des infirmières et infirmiers du Québec (2009). La pratique infirmière en santé mentale. Une contribution essentielle à consolider, Rapport du comité d'experts sur la pratique infirmière en santé mentale et en soins psychiatriques, Ordre des infirmières et infirmiers du Québec, ISBN 978-2-89229-487-3, Westmount, Québec

Ouadahi, Y., Lesage, A., Rodrigue, J. \& Fleury, M.-J. (2009). Les problèmes de santé mentale sont-ils détectés par les omnipraticiens? Regard sur la perspective des omnipraticiens selon les banques de données administratives. Santé mentale au Québec, Vol. 34. No. 1 (Spring 2009), pp. 161-172, ISSN 0383-6320

Parslow, R.A. \& Jorm, A.F. (2000). Who uses mental health services in Australia? An analysis of data from the National Survey of Mental Health and Wellbeing. Australian and New Zealand Journal of Psychiatry, Vol. 34, No. 6, (December 2000), pp. 997-1008, ISSN 0004-8674

Pawlenko, N. (2005). Collaborative Mental Health Care in Primary Health Care Settings Across Canada. A Policy Review. Canadian Collaborative Mental Health Initiative. Health Canada's Primary Health Care Transition Fund, ISBN 1-896014-78-X, Mississauga, Ontario

Perrault, M., Wiethaueper, D., Perreault, N., Bonin, J.P., Brown, T.G. \& Brunaud, H. (2009). Meilleures pratiques et formation dans le contexte de continuum en santé mentale et en toxicomanie: le programme de formation croisée du sud-ouest de Montréal. Santé mentale au Québec, Vol. 34, No. 1, (Spring 2009), pp. 143-160, ISSN 0383-6320

Pescosolido, B.A., Gardner, C.B. \& Lubell, K.M. (1998). How people get into mental health services: stories of choice, coercion and "muddling through" from "First-timers". Social Science \& Medicine, Vol. 46, No. 2, (January 1998), pp. 275-286, ISSN 0277-9536

Provan, K.G. \& Milward, B.H. (1995). Preliminary Theory of Interorganizational Network Effectiveness: A Comparative Study of Four Community Mental Health Systems. Administrative Science Quarterly, Vol. 40, No. 1, (March 1995), pp. 1-33, ISSN 00018392

Pong, R. (2005). Répartition géographique des médecins au Canada : au-delà du nombre et du lieu. Institut canadien d'information sur la santé, ISBN 1-55392-738-9, Ottawa, Canada

Reavley, N.J. \& Jorm, A.F. (2010). The quality of mental disorder information websites: A review. Patient Education and Counselling, Vol. 85, No. 2, (November 2010), p.p. 216e25, ISSN 0738-3991

Regier, D.A., Farmer, M.E., Rae, D.S., Locke, B.Z., Keith, S.J., Judd, L.L. \& Goodwin, F.K. (1990). Comorbidity of mental disorders with alcohol and other drug abuse. Results from the Epidemiological Catchment Area (ECA) Study. Journal of the American Medical Association, Vol. 264, No. 19, (November 1990), pp. 2511-2518, ISSN 00987484 
Rhodes, A.E. \& Fung, K. (2004). Self-reported use of mental health services versus administrative records: care to recall? International Journal of Methods in Psychiatric Research, Vol. 13, No. 3, (August 2004), pp. 165-175, ISSN 1094-8931

Rockman, P., Salach, L., Gotlib, D., Cord, M. \& Turner, T. (2004). Shared mental health care. Model for supporting and mentoring family physicians. Canadian Family Physician, Vol. 50, No. 3, (March 2004), pp. 397-402, ISSN 008-350X

Rothman, A.A. \& Wagner E.H. (2003). Chronic Illness Management: What is the role of primary care? Annals of Internal Medicine, Vol. 138, No. 3, (February 2003), pp. 256262, ISSN 0003-4819

Rush, B.R., Urbanoski, K.A., Bassani, D.G., Castel, S. \& Wild, T.W. (2010). The epidemiology of co-occurring substance use and other mental disorders in Canada: Prevalence, service use and unmet needs. In Mental disorder in Canada; an epidemiological perspective, Cairney, J. \& Streiner, D.L. (Eds.), pp. 144-169, University of Toronto Press, ISBN 978-8020-9202-1, Toronto, Buffalo, London

Savard, I. \& Rodrigue, J. (2007). Des omnipraticiens à la grandeur du Québec. Évolution des effectifs et des profils de pratique. Données de 1996-1997 à 2005-2006. Direction de la planification et de la régionalisation - Fédération des Médecins Omnipraticiens du Québec (FMOQ), ISBN 978-550-55141-6, Québec, Canada

Schmitz, N., Wang, J., Malla, A. \& Lesage, A. (2007). Joint effect of depression and chronic conditions on disability: results from a population-based study. Psychosomatic Medicine, Vol. 69, No. 4, (May 2007), pp. 332-338, ISSN 0333-3174

Seekles, W., van Straten, A., Beekman, A., van Marwijk, H. \& Cuijpers, P. (2009). Stepped care for depression and anxiety: from primary care to specialized mental health care: a randomised controlled trial testing the effectiveness of a stepped care program among primary care patients with mood or anxiety disorders. BMC Health Services Research, Vol. 9, (June 2009), pp. 90, ISSN 1472-6963

Shortell, S.M., Gillies, R.R. \& Anderson, D.A. (1994). The new world of managed care: creating organized delivery systems.. Health Affairs, Vol. 13, No. 5 (Winter 1994), pp. 46-64, ISSN 1544-5208

Simonet, D. (2009). Changes in the delivery of primary care and in private insurers' role in United Kingdom, Italy, Germany, Swittzerland and France. Journal of Medical Marketing, Vol. 9, No. 2, (June 2009), pp. 96-103, ISSN 1745-7904

Skinner, W., O'Grady, C., Bartha, C. \& Parker, C. (2004). Les troubles concomitants de toxicomanie et de santé mentale, Centre de toxicomanie et de santé mentale, ISBN 088868-475-4, Toronto, Ontario

Slade, M., Leese, M., Cahill, S., Thornicroft, G. \& Kuipers, E. (2005). Patient-rated mental health needs and quality of life improvement. British Journal of Psychiatry, Vol. 187, (September 2005), pp. 256-261, ISSN 0007-1250

Smith, G.C. (2009). From consultation-liaison psychiatry to integrated care for multiple and complex needs. Australian and New Zealand Journal of Psychiatry, Vol. 43, No. 1, (January 2009), pp. 1-12, ISSN 0004-8674

Starfield, B. (2008). The importance of Primary Health Care in Health Systems. Qatar-EMRO Primary Health Care Conference Doha, Qatar, June 27 2011. Available from: gis.emro.who.int/HealthSystemObservatory/Workshops/QatarConference/PPt\% 20converted $\% 20$ to $\% 20$ PDF/Day $\% 202 / \mathrm{P} \% 20$ Reg $\%$ 20Experiences $\% 20$ and $\% 20$ Innov ative \%20Solution/Dr\%20B.\%20Starfield \%20-\%20Importance\%20of\%20PC.pdf 
Starfield, B., Shi, L. \& Macinko, J. (2005). Contribution of primary care to health systems and health. Milbank Quarterly, Vol. 83, No. 3, pp. 457-502, ISSN 0887-378X

Starfield, B. (1998). Primary care visits and health policy. Canadian Medical Association Journal, Vol. 159, No. 7, (October 1998), pp. 795-796, ISSN 0820-3946

Statistics Canada (2002). Santé mentale et bien-être, Enquête sur la santé dans les collectivités canadiennes de 2002 (ESCC-2002); June 27 2011. Available from: dsp-psd.pwgsc.gc.ca/Collection/Statcan/82-617-X/82-617-XIF.html

The Commonwealth Fund (2008). W2008 Commonwealth Fund International Health Policy Survey of Sicker adults June 29 2011, Available from: www.commonwealthfund.org/Content/Surveys/2008/2008-CommonwealthFundInternational-Health-Policy-Survey-of-Sicker-Adults.aspx

Tempier, R., Meadows, G.N., Vasiliadis, H.M., Mosier, K.E., Lesage, A., Stiller, A., Graham, A. \& Lepnurm, M. (2009) Mental disorders and mental health care in Canada and Australia: comparative epidemiological findings. Social Psychiatry and Psychiatric Epidemiology, Vol. 44, No. 1, (January 2009), pp. 63-72, ISSN 0933-7954

Trifiro, G., Barbui, C., Spina, E., Moretti, S., Tari, M., Alacqua, M., Caputi, A.P., UVEC Group \& Arcoraci, V. (2007). Antidepressant drugs: prevalence, incidence and indication of use in general practice of Southern Italy during the years 2003-2004. Pharmacoepidemiology and Drug Safety, Vol. 16, No. 5, (May 2007), pp. 552-559, ISSN 1099-1557

Tylee, A. (2006). Identifying and managing depression in primary care in the United Kingdom. Journal of Clinical Psychiatry, Vol. 67, Suppl. 6, (2006), pp. 41-45, ISSN 0160-6689

Tyrer, P. (2009). Are general practitioners really unable to diagnose depression? Lancet, Vol. 374, No. 9690, (August 2009), pp. 589-590, ISSN 0140-6736

Upshur, C. \& Weinreb, L. (2008). A survey of primary care provider attitudes and behaviors regarding treatment of adult depression: what changes after a collaborative care intervention? Primary Care Companion of the Journal of Clinical Psychiatry, Vol. 10, No. 3, (June 2008), pp. 182-186, ISSN 2150-1319

Valenstein, M., Klinkman, M., Becker, S., Blow, F.C., Barry, K.L., Sattar, A. \& Hill, E. (1999). Concurrent treatment of patients with depression in the community: provider practices, attitudes, and barriers to collaboration. Journal of Family Practice, Vol. 48, No. 3, (March 1999), pp. 180-187, ISSN 1091-7527

Van Rijswijk, E., van Hout, H., van de Lisdonk, E., Zitman, F. \& van Weel, C. (2009). Barriers in recognising, diagnosing and managing depressive and anxiety disorders as experienced by Family Physicians; a focus group study. BMC Family Practice, Vol. 10, (July 2009), pp. 52, ISSN 1471-2296

Vasiliadis, H.M., Lesage, A., Adair, C., Wang, P.S. \& Kessler, R.C. (2007). Do Canada and the United States differ in prevalence of depression and utilization of services. Psychiatric Services, Vol. 58, No. 1, (January 2007), pp. 63-71, ISSN 1075-2730

Wagner, E., Austin, B.T., Davis, C., Hindmarsh, M., Schaefer, J. \& Bonomi, A. (2001). Improving chronic illness care: translating evidence into action. Health Affairs, Vol. 20, No. 6, (November-December 2001), pp. 64-78, ISSN 1544-5208

Walters, P., Tylee A. \& Goldberg D. (2008). Psychiatry in primary care. In Essential psychiatry, Murray, R.M., Kendler, K.S., McGuffin, P., Wessely, S. \& Castle, D.J. (Eds.), pp. 479- 
497, Cambridge University Press, ISBN 978-0-521-6408-6, Cambridge, United Kingdom

Wang, P.S., Aguilar-Gaxiola, S., Alonso, J., Angermeyer, M.C., Borges, G., Bromet, E.J., Bruffaerts, R., de Girolamo, G., de Graaf, R., Gureje, O., Haro, J.M., Karam, E.G., Kessler, R.C., Kovess, V., Lane, M.C., Lee, S., Levinson, D., Ono, Y., Petukhova M., Posada-Villa, J., Seedat, S. \& Wells, J.E. (2007). Use of mental health services for anxiety, mood, and substance disorders in 17 countries in the WHO world mental health surveys. Lancet, Vol. 370, No. 9590, (September 2007), pp. 841-850, ISSN 0140-6736

Wang, P.S., Berglund, P., Olfson, M., Pincus, H.A., Wells, K.B. \& Kessler, R.C. (2005a). Failure and delay in initial treatment contact after first onset of mental disorders in the National Comorbidity Survey Replication, Archives of General Psychiatry, Vol. 62, No. 6, (June 2005), pp. 603-613, ISSN 0003-990X

Wang, P.S., Lane, M., Olfson, M., Pincus, H.A., Wells, K.B. \& Kessler, R.C. (2005b). Twelvemonth use of mental health services in the United States: results from the National Comorbidity Survey Replication. Archives of General Psychiatry, Vol. 62, No. 6, (June 2005), pp. 629-640, ISSN 0003-990X

Wang, P.S., Berglund. P. \& Kessler, R.C. (2000). Recent care of common mental disorders in the United States: prevalence and conformance with evidence-based recommendations. Journal of General Internal Medicine, Vol. 15, No. 5, (May 2000), pp. 284-292, ISSN 0084-8734

Weinreb, L., Gelberg, L., Arangua, L. \& Sullivan, M. (2005). Disorders and health problems: overview, in Encyclopedia of Homelessness, Vol. 1, Levinson, D. (Ed), pp. 115-123, Sage Publications, ISBN 0-7619-2751-4, Thousand Oaks, California

Williams, J.J. Jr, Gerrity, M., Holsinger, T., Dobscha, S., Gaynes, B. \& Dietrich, A. (2007). Systematic review of multifaceted interventions to improve depression care. General Hospital Psychiatry, Vol. 29, No. 2, (April 2007), pp. 91-116, ISSN 1945-4953

World Health Organization (2008). The World Health Report 2008: Primary Health Care (Now More than Ever), World Health Organization, ISBN 13-9789241563734, Geneva, Switzerland

World Health Organization (2006). The World Health Report 2006: Working together for health. World Health Organization, ISBN 92-4-156317-6, Geneva, Switzerland

World Health Organization (2001). The World Health Report 2001: Mental health: new understanding, new hope. World Health Organization, ISBN 92-4-156201-3, Geneva, Switzerland

World Health Organization (1978). Declaration of Alma Ata, Primary Health Care: Report of the International Conference on Primary Health Care, Alma-Ata, USSR, 6-12 September 1978, Geneva, Switzerland

Wright, M.J., Harmon, K.D., Bowman, J.A., Lewin, T.J. \& Carr, V.J. (2005). Caring for depressed patients in rural communities: general practitioners' attitudes, needs and relationships with mental health services. Australian Journal of Rural Health, Vol. 13, No.1, (February 2005), pp. 21-27, ISSN 1038-5282

Younes, N., Gasquet, I., Gaudebout, P., Chaillet, M.P., Kovess, V., Falissard, B. \& Hardy Bayle, M.C. (2005). General practitioners' opinions on their practice in mental health and their collaboration with mental health professionals. BMC Family Practice, Vol. 6, No. 1, (May 2005), pp. 18, ISSN 1471-2296 


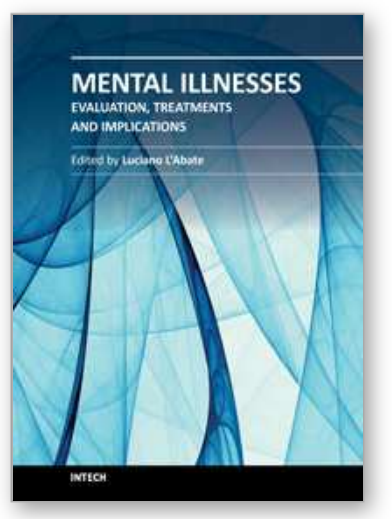

\author{
Mental IIInesses - Evaluation, Treatments and Implications \\ Edited by Prof. Luciano LAbate
}

ISBN 978-953-307-645-4

Hard cover, 476 pages

Publisher InTech

Published online 13, January, 2012

Published in print edition January, 2012

In the book "Mental Illnesses - Evaluation, Treatments and Implications" attention is focused on background factors underlying mental illness. It is crucial that mental illness be evaluated thoroughly if we want to understand its nature, predict its long-term outcome, and treat it with specific rather than generic treatment, such as pharmacotherapy for instance. Additionally, community-wide and cognitive-behavioral approaches need to be combined to decrease the severity of symptoms of mental illness. Unfortunately, those who should profit the most by combination of treatments, often times refuse treatment or show poor adherence to treatment maintenance. Most importantly, what are the implications of the above for the mental health community? Mental illness cannot be treated with one single form of treatment. Combined individual, community, and socially-oriented treatments, including recent distance-writing technologies will hopefully allow a more integrated approach to decrease mental illness world-wide.

\title{
How to reference
}

In order to correctly reference this scholarly work, feel free to copy and paste the following:

Marie-Josée Fleury and Guy Grenier (2012). Primary Mental Healthcare and Integrated Services, Mental IIInesses - Evaluation, Treatments and Implications, Prof. Luciano LAbate (Ed.), ISBN: 978-953-307-645-4, InTech, Available from: http://www.intechopen.com/books/mental-illnesses-evaluation-treatments-andimplications/primary-mental-healthcare-and-integrated-services

\section{INTECH}

open science | open minds

\section{InTech Europe}

University Campus STeP Ri

Slavka Krautzeka 83/A

51000 Rijeka, Croatia

Phone: +385 (51) 770447

Fax: +385 (51) 686166

www.intechopen.com

\section{InTech China}

Unit 405, Office Block, Hotel Equatorial Shanghai

No.65, Yan An Road (West), Shanghai, 200040, China

中国上海市延安西路65号上海国际贵都大饭店办公楼 405 单元

Phone: +86-21-62489820

Fax: $+86-21-62489821$ 
(C) 2012 The Author(s). Licensee IntechOpen. This is an open access article distributed under the terms of the Creative Commons Attribution 3.0 License, which permits unrestricted use, distribution, and reproduction in any medium, provided the original work is properly cited. 